\title{
Regional climate projection over South Korea simulated by the HadGEM2-AO and WRF model chain under RCP emission scenarios
}

\author{
Eun-Soon $\mathrm{Im}^{1}{ }^{1}$ Joong-Bae $\mathrm{Ahn}^{2, *}$, Se-Ra Jo ${ }^{2}$ \\ ${ }^{1}$ Singapore-MIT Alliance for Research and Technology (SMART), \\ Center for Environmental Sensing and Modeling (CENSAM), 138602, Singapore \\ ${ }^{2}$ Division of Earth Environmental System, Pusan National University, Pusan 609735, South Korea
}

\begin{abstract}
This study assesses the regional climate projection newly generated within the framework of the national downscaling project in South Korea. To obtain fine-scale climate information $(12.5 \mathrm{~km})$, dynamical downscaling of the HadGEM2-AO global projections forced by the representative concentration pathway (RCP4.5 and RCP8.5) scenarios is performed using the Weather Research and Forecasting (WRF) modeling system. Changes in temperature and precipitation in terms of long-term trends, daily characteristics and extremes are presented by comparing two 30 yr periods (2041-2070 vs. 2071-2100) in which increasing rates of emission forcing between the RCP4.5 and RCP8.5 scenarios are relatively similar and quite different, respectively. The temperature increase presents a relevant trend, but the degree of warming varies in different periods and emission scenarios. While the temperature distribution from the RCP8.5 projection is continuously shifted toward warmer conditions by the end of the 21st century, the RCP4.5 projection appears to stabilize warming in accordance with emission forcing. This shift in distribution directly affects the magnitude of extremes, which enhances extreme hot days but reduces extreme cold days. Precipitation changes, however, do not respond monotonically to emission forcing, as they exhibit less sensitivity to different emission scenarios. An enhancement of high intensity precipitation and a reduction of weak intensity precipitation are discernible, implying an intensified hydrologic cycle. Changes in return levels of annual maximum precipitation suggest an increased probability of extreme precipitation with $20 \mathrm{yr}$ and $50 \mathrm{yr}$ return periods.
\end{abstract}

KEY WORDS: Regional climate projection $\cdot$ Dynamical downscaling $\cdot$ RCP scenario

\section{INTRODUCTION}

Projections of changes in the climate system under global warming are widely generated using global climate models (GCMs) forced by emission scenarios of anthropogenic greenhouse gases (GHGs). As a part of a contribution to the Fifth Assessment Report (AR5) of the IPCC (IPCC 2013), the National Institute of Meteorological Research of the Korea Meteorological Administration (KMA) is jointly participating in the Coupled Model Intercomparison Project phase 5 (CMIP5; Taylor et al. 2012) with the

\footnotetext{
${ }^{*}$ Corresponding author: jbahn@pusan.ac.kr
}

Met Office Hadley Centre using the Hadley Centre Global Environmental Model version 2 coupled with atmosphere-ocean configuration (HadGEM2-AO) (Baek et al. 2013). Climate change experiments using HadGEM2-AO within the framework of CMIP5 have played an important role in assessing future climate at the national standards level in South Korea.

Although climate projections produced by GCMs produce fundamental information to estimate the possible consequences of the future climate, their coarse resolution prevents them from adequately

(C) The authors 2015. Open Access under Creative Commons by Attribution Licence. Use, distribution and reproduction are unrestricted. Authors and original publication must be credited. 
capturing local forcings such as complex topography and surface heterogeneity that modulate the climate signal at fine scales (Giorgi et al. 2009). Therefore, global projection lacks the potential for practical application to various impact assessments (e.g. surface hydrology, agriculture) that are mostly valid in regional and local sectors. Even a massive increase in computational capacity will not allow GCMs to run with sufficiently high resolution, because reliable climate projection would require statistics based on long-term ensemble simulations that consider as many members as possible. One method for overcoming this limitation and increasing the detail of global projections is the use of a regional climate model (RCM) embedded within GCMs. In particular, numerous modeling studies have confirmed that RCMs with relatively high resolution simulate climatic characteristics more skillfully than do GCMs over East Asia (e.g. Gao et al. 2001，2011，2012, 2013, Im et al. 2007, Yu et al. 2010, Zou \& Zhou 2013, Lee et al. 2014, Oh et al. 2014, Hong \& Ahn in press). Based on a series of simulations, Gao et al. (2006) highlight the role of adequate spatial resolution to resolve the physical and dynamical process in simulating the climate over East Asia.

In this regard, several research groups in South Korea have performed dynamical downscaling of the HadGEM2-AO global projections forced by the representative concentration pathway $(\mathrm{RCP}$; Moss et al. 2010) scenarios using different RCMs. These experiments were performed in accordance with the East Asian configuration of the Coordinated Regional Climate Downscaling Experiment (CORDEX; Giorgi et al. 2009). For example, Lee et al. (2014) conducted downscaling using Global/Regional Integrated Model System (GRIMs)-Regional Model Program (RMP) and assessed future climate change (2025-2050) with respect to the current climate (1980-2005). Oh et al. (2014) performed the same experiments and analysis except for using the Regional Climate Model version 4 (RegCM4). Both studies suggested that their downscaled results showed reasonable performance in simulating a current reference climate over East Asia, including the Korean peninsula. Regarding future projection, they also derived a similar conclusion with intensified heavy precipitation and reduced weak precipitation over Korea. More specifically, Oh et al. (2014) report that mean precipitation in summer over Korea is projected to increase by $44 \%$ (24\%) for the RCP4.5 (RCP8.5) scenario during 2031-2050 relative to $1986-2005$. This increment is significantly greater than that of any other region in East Asia, and interestingly, precipitation likely increases more under RCP4.5 projection than RCP8.5 projection during 2031-2050. Since both studies utilized the downscaling results with the same boundary condition (i.e. HadGEM2-AO) that we used, they are exemplary references for supporting our findings and compensating for the limitation due to a single RCM (i.e. Weather Research and Forecasting [WRF]) in this study.

However, the standard resolution of $50 \mathrm{~km}$ under the CORDEX configuration remains insufficient to capture complicated physiographical features which significantly affect the weather and climate system over Korea. Indeed, the Korean peninsula is a representative region that highlights the need for a high-resolution modeling system, because its geographical area is relatively small and it has a complicated mountainous terrain (Im et al. 2006, 2007). Im et al. (2007) showed that only nested domain simulation $(20 \mathrm{~km})$ is capable of producing extreme precipitation episodes that the mother domain $(60 \mathrm{~km})$ fails to capture from the doublenested RegCM3 simulation. Lee \& Hong (2014) also demonstrated the added value to downscaled climate extremes over South Korea by the increased resolution of an RCM throughout the comparison of GRIMs-RMP simulations with 2 different resolutions (12.5 vs. $50 \mathrm{~km})$. On this research foundation, the national downscaling project of Korea, which aims to produce $12.5 \mathrm{~km}$ fine-scale climate multi-model ensemble information focusing on the Korean peninsula with different RCMs but the same driving fields (HadGEM2-AO), is progressing as the next step to the CORDEX experiments.

In this study, we present the downscaled results $(12.5 \mathrm{~km})$ of the HadGEM2-AO projection under the RCP4.5 and RCP8.5 emission scenarios using the WRF modeling system. We investigate the possible changes in future climate with a focus on comparing two 30 yr periods, namely, 2041-2070 and 2071-2100, which enables us to assess the climate change behavior at different time periods in response to the RCP4.5 and RCP8.5 emission scenarios. Our analysis is primarily centered on both the long-term trend on an annual basis and the characteristics of extremes using daily temperature and precipitation. As the downscaled data documented in this study will serve as one of the ensemble members for the development of a climate change projection on behalf of the national standard scenario, this study may provide baseline information to contribute to the national downscaling project in Korea. 


\section{MODEL DESCRIPTION AND EXPERIMENTAL DESIGN}

\subsection{WRF description}

For fine-scale climate information over South Korea, we perform dynamical downscaling of the HadGEM2AO global projection forced by the RCP4.5 and RCP8.5 scenarios using the WRF modeling system (version 3.4; Skamarock et al. 2008). The WRF is a next-generation meso-scale numerical model with a wide user community, and the Advanced Research WRF solver developed at the National Center for Atmospheric Research (NCAR) was used for the dynamic core, which is a fully compressible and nonhydrostatic model (Skamarock et al. 2008).

The physical parameterizations include the MoninObukhov similarity for surface layer scheme (Jiménez et al. 2012), Noah land surface scheme (Chen \& Dudhia 2001), Yonsei University (YSU) planetary boundary layer scheme (Hong et al. 2006), NCAR Community Atmospheric Model (CAM) longwave and shortwave radiation scheme (Collins et al. 2002), Single-Moment 3-class (WSM3) microphysics scheme (Hong et al. 2004) and the Kain-Fritsch cumulus scheme (Kain \& Fritsch 1993). We select this combination of physical schemes based on previous studies to optimize the WRF performance through various sensitivity experiments over the domain centered at the Korean peninsula (e.g. Cho \& Lee 2006, Hong \& Lee 2009, Lim \& Hong 2010, Ahn et al. 2013).

\subsection{Experimental design and data used}

Fig. 1 shows the model domain and topography used for the WRF simulation. The domain covers Northern East Asia centered at the Korean peninsula (center: $37.5^{\circ} \mathrm{N}, 127.5^{\circ} \mathrm{E}$ ). To emphasize the resolution effect, we also provide the topography of HadGEM2-AO $\left(1.875^{\circ} \times 1.250^{\circ}\right)$ over the WRF domain as a reference. This comparison clearly demonstrates how the representation of topography over a narrow peninsula depends critically on the model resolution. The topography of HadGEM2AO shows hardly any mountain slope in the Korean peninsula. This mal-representation of geographical characteristics could negatively affect the model performance in simulating local and regional climates. On the other hand, the WRF modeling system $(12.5 \mathrm{~km})$ describes much more realistic features of 2 relevant mountains, such as the Taebaek Mountains, extending from north to south along the eastern coastal regions of the Korean peninsula, and the Sobaek Mountains located in the south-central regions of the peninsula. Indeed, the maximum height of WRF topography $(608 \mathrm{~m})$ over South Korea is much closer to the height of the highest observational station (772 m), compared to that of HadGEM2-AO (148 m) (Fig. 1).

For the downscaling of the reference climate, WRF simulation spans 32 yr from 1 January 1979 until 31 December 2010, and the first 2 yr simulation is
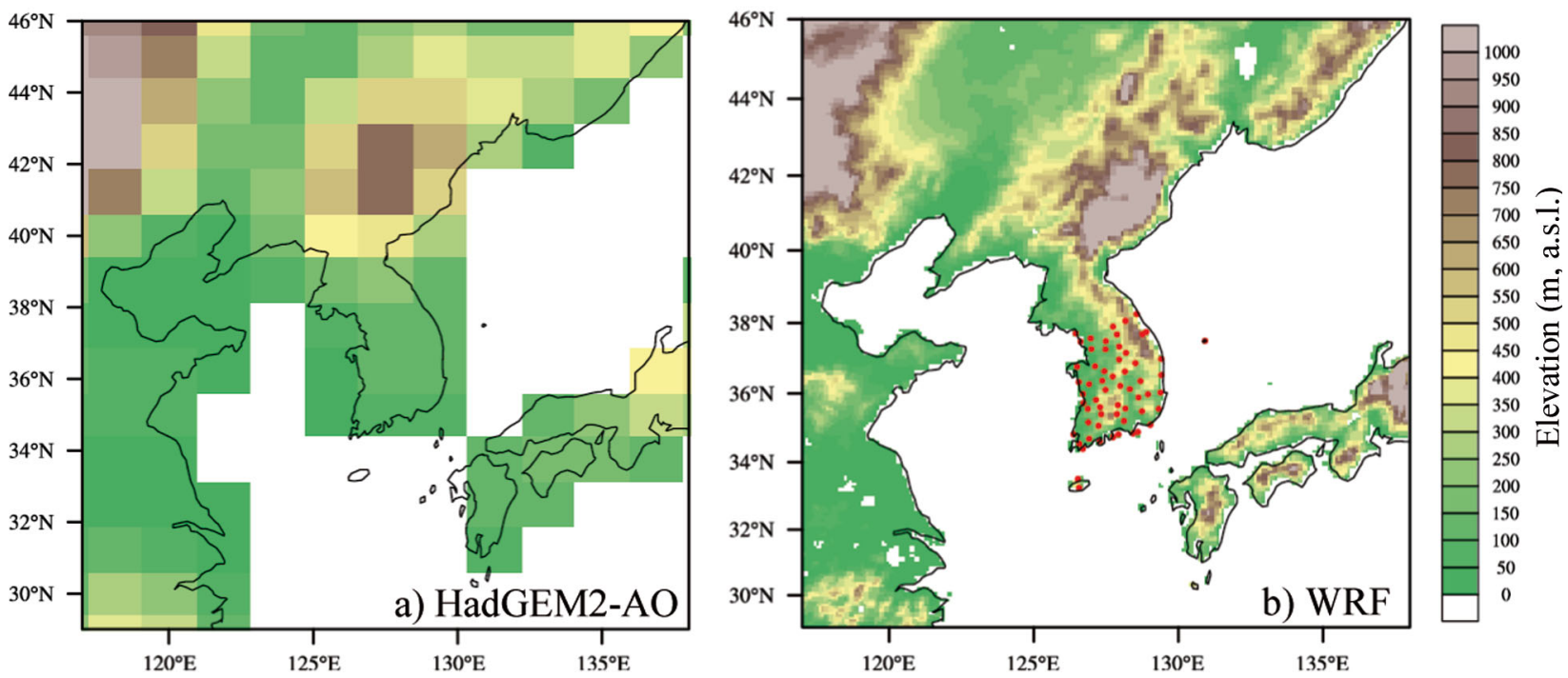

Fig. 1. Topography used for (a) HadGEM2-AO $\left(1.875^{\circ} \times 1.25^{\circ}\right)$ and $(\mathrm{b}) \mathrm{WRF}(12.5 \mathrm{~km})$ simulations over the WRF domain. Red dots over South Korea in (b) indicate the locations of 60 observational stations used for validating the reference (REF) simulation 
excluded in the analysis as a spin-up period. For the future projection, WRF simulation spans $82 \mathrm{yr}$ from 1 January 2019 until 31 December 2100, and the first $2 \mathrm{yr}$ simulation is also excluded as a spin-up period. The initial and boundary conditions to drive the WRF modeling system are obtained from the HadGEM2AO projection simulated under the CMIP5 experiment design (Baek et al. 2013). Two RCP scenarios, namely RCP4.5, which is a stabilization scenario without overshooting pathways to $4.5 \mathrm{~W} \mathrm{~m}^{-2}$, and RCP8.5, which is a rising pathway leading to $8.5 \mathrm{~W}$ $\mathrm{m}^{-2}$ by 2100 , are used. Since the historical period based on atmospheric concentration observations extends to 2005, the reference simulation during 20062010 is forced by the GHG concentrations from the RCP8.5 scenario. However, this should not introduce a significant problem because GHG concentrations for this 5 yr period are not greatly different depending on the scenario (e.g. $\mathrm{CO}_{2}$ concentration averaged over 2006-2010: RCP4.5: $384.82 \mathrm{ppm}$, RCP8.5: $384.87 \mathrm{ppm})$. This study assigns the recent $30 \mathrm{yr}$ of 1981-2010 as a reference period for matching future scenarios with two 30 yr periods (2041-2070 and 2071-2100). Hereinafter, the WRF simulation during the reference period is denoted as 'REF' while WRF simulations during the future periods under the RCP4.5 and RCP8.5 scenarios are denoted as 'RCP4.5' and 'RCP8.5', respectively.

The reference simulation (e.g. REF) is evaluated against both global gridded data and station data situated over South Korea. The Climate Research Unit (CRU) Time Series 2.0 (TS2.0) with a horizontal resolution of $0.5^{\circ} \times 0.5^{\circ}$ over only land area (Mitchell et al. 2004) is used for the calculation of the bias and root mean square error (RMSE) in order to estimate the basic performance of both the HadGEM2-AO and WRF simulations. For the validation of WRFdownscaled results in more detail, we use daily observational data from 60 meteorological stations whose quality control was maintained by KMA during the same period (1981-2010). The red dots in Fig. 1(b) show the locations of observational stations used in this study. The locations include both lowelevation and high-elevation stations and are relatively evenly distributed. We compare simulated variables at the grid points closest to the stations with individual observational values. The model grid $(12.5 \mathrm{~km})$ is less than the mean distance of observational stations (about $30 \mathrm{~km}$ ), and there is no station point that matches with the same grid value. In general, the high model resolution justifies the comparison between station data and the closest grid point model data (Im et al. 2008b, 2011).

\section{RESULTS}

The model chain composed of $1 \mathrm{RCM}$ and $1 \mathrm{GCM}$ limits the robustness of the result because of its dependence on the selected projection. Hence, the use of a different model combination may afford a different conclusion. Although this study does not provide multi-model ensemble projection, we assess the basic performance of HadGEM2-AO and WRF in simulating the reference climate in an attempt to justify the use of 1 global and 1 regional model. Beak et al. (2013) demonstrate the skill with which HadGEM2AO simulates the present climate simulated, based on the evaluation index defined by the aggregated and normalized errors in 19 different key climate quantities, particularly over East Asia (Fig. 3 in Beak et al. 2013). Hong \& Ahn (in press) also demonstrate that HadGEM2-AO shows superior performance in simulating early summer (MJJ) precipitation compared to CMIP5 multi-model ensemble mean in both quantitative (e.g. bias and RMSE) and qualitative (e.g. spatial distribution) aspects over Northeast Asia (Figs. 3 \& 4 in Hong \& Ahn in press). More specifically, the bias and RMSE of summer precipitation derived from HadGEM2-AO-1.27 and $1.5 \mathrm{~mm} \mathrm{~d}^{-1}$, respectivelyreveal a superior performance compared to the equivalent values of 2.12 and $2.2 \mathrm{~mm} \mathrm{~d}^{-1}$, respectively, from the CMIP5 multi-model ensemble mean with respect to TRMM (Tropical Rainfall Measuring Mission) observation. Therefore, we consider that HadGEM2AO satisfies the minimum requirement for downscaling over our target region. In addition to the comparison between the HadGEM2-AO and CMIP5 multimodel ensemble, Hong \& Ahn (in press) present a relevant improvement of the summer precipitation from WRF-downscaled results over the Korean peninsula. While HadGEM2-AO and the CMIP5 multi-model ensemble fail to capture the strong magnitude of the localized maxima related to the stationary front over Korea, high-resolution WRF reproduces a pattern that is closer to the TRMM observation. Furthermore, WRF is capable of reproducing the major characteristics of monsoon evolution (e.g. the speed of northward movement) similar to those in TRMM, in spite of some deficiency.

Here, the performance of WRF-downscaled results in simulating the seasonal mean temperature and precipitation during the reference period (1981-2010) is quantitatively evaluated over Korea against both observations and the HadGEM2-AO global projection used as the initial and boundary conditions. In general, WRF is capable of reproducing the main features of the seasonal variation seen in the ob- 
Table 1. Bias and RMSE of seasonal mean (JJA and DJF) temperature and precipitation over South Korea $\left(33^{\circ}-38.65^{\circ} \mathrm{N}\right.$, $124^{\circ}-130.5^{\circ} \mathrm{E}$ ) from HadGEM2-AO and WRF simulation against the Climate Research Unit (CRU) observation for the reference period (1981-2010)

\begin{tabular}{|lcccc|}
\hline & \multicolumn{5}{c}{ Temperature $\left({ }^{\circ} \mathrm{C}\right)$} & \multicolumn{3}{c|}{ Precipitation $\left(\mathrm{mm} \mathrm{d}^{-1}\right)$} \\
& Bias & RMSE & Bias & RMSE \\
\hline Summer (JJA) & & & & \\
HadGM2-AO & 0.2 & 1.59 & -3.19 & 3.45 \\
WRF & -1.42 & 1.79 & -1.14 & 1.48 \\
Winter (DJF) & & & & \\
HadGM2-AO & 1.66 & 2.2 & 0.08 & 0.17 \\
WRF & 0.39 & 1.66 & 1.02 & 1.37 \\
\hline
\end{tabular}

served pattern, and of better resolving regional- and local-scale details compared to the HadGEM2-AO global projection (see Figs. 2 \& 3 in Ahn et al. 2013). For the objective measure of their performances focusing on the Korean peninsula $\left(33^{\circ}-38.65^{\circ} \mathrm{N}\right.$, $\left.124^{\circ}-130.5^{\circ} \mathrm{E}\right), \mathrm{T}^{2}$ able 1 presents the quantitative metrics of the HadGEM2-AO and WRF performance during the summer (JJA) and winter (DJF) seasons. In general, the WRF's systematic biases appear to be inherited from the HadGEM2-AO global projection. However, the WRF-downscaled results substantially reduce the dry bias of summer precipitation and warm bias of winter temperature produced in HadGEM2-AO, as evident in Table 1. In contrast to the significant improvements of summer precipitation, WRF tends to worsen the wet bias of winter precipitation. This feature is associated with heavy snowfall along the high mountainous region (see Fig. 5 in Ahn et al. 2013), and thus indicates that WRF shows more reasonable spatial details which properly reflect the complex topographical feature of the Korean peninsula. For temperature, WRF tends to simulate relatively lower temperature than HadGEM2-AO due to the higher elevation of WRF terrain. This leads to a positive effect for winter temperature (i.e. reduction of warm bias from HadGEM2AO), but a negative effect for summer temperature (i.e. enhancement of cold bias). The bias pattern denoted in Table 1 is not limited to our simulation, but rather seems to be a typical error found in many other regional climate simulations over East Asia, including the Korean peninsula. The magnitude of biases averaged over Korea are quantitatively less or similar to other downscaled results using the same global projection as the initial and boundary reported by Oh et al. (2014), Hong et al. (2013) and Lee $\&$ Hong (2014). For conciseness, we avoid duplicating the validation of the same features that appeared in
Ahn et al. (2013) and Hong \& Ahn (in press). Instead, in this study, we focus on the long-term trends, extremes and daily statistics of temperature and precipitation over Korea.

\subsection{Long-term trends of temperature and precipitation}

We begin our analysis with the time series of annually averaged temperature anomalies. Fig. 2 presents the anomalies of daily mean temperature $\left(T_{\text {mean }}\right)$, daily maximum temperature above $95 \%\left(T_{\max 95}\right)$, and daily minimum temperature below $5 \%\left(T_{\min 05}\right)$ on an annual basis over South Korea throughout the entire integration period from the WRF simulation. The anomalies are obtained by subtracting the climatological mean of the reference period (1981-2010), which enables systematic biases in the underlying model to be partly eliminated, and emphasis is placed on the trends in climate change with respect to the reference climate. We also display the observed estimates archived at the Korean climate stations during the reference period in order to validate the model performance.

During the reference period, temperature shows a gradually increasing pattern, with the trend being statistically significant at the $95 \%$ confidence level (see Table 2). Compared to $T_{\text {mean }}$ and $T_{\max 95}, T_{\min 05}$ exhibits a noticeable warming. In general, REF is able to capture the major characteristics of temporal evolution in temperature, showing a similarity with the observed pattern in terms of variability range and trend, except for the somewhat steeper slope of $T_{\max 95}$. Moving to the future projection for the $21 \mathrm{st}$ century, positive anomalies from both RCP4.5 and RCP8.5 become dominant compared to REF. However, the degree of warming between RCP4.5 and RCP8.5 shows a different behavior, presumably in response to feeding the different GHG concentrations from different emission scenarios. The 2 scenarios clearly diverge after about 2070. More specifically, $T_{\text {mean }}$ derived from RCP8.5 increases continuously by $>5^{\circ} \mathrm{C}$ at the end of the 21 st century, whereas $T_{\text {mean }}$ derived from RCP4.5 appears to stabilize the warming after the mid to late 21st century, in accordance with the GHG concentrations. By comparison, the increasing rate of $T_{\min 05}$ is stronger than that of $T_{\max 95}$, which is in line with many other studies that assess future climate changes (e.g. Im et al. 2011).

Table 2 summarizes the basic statistics of trends derived from the $T_{\text {mean }}, T_{\max 95}$, and $T_{\min 05}$ temporal evolution seen in Fig. 2. Since the temporal evolutions of 

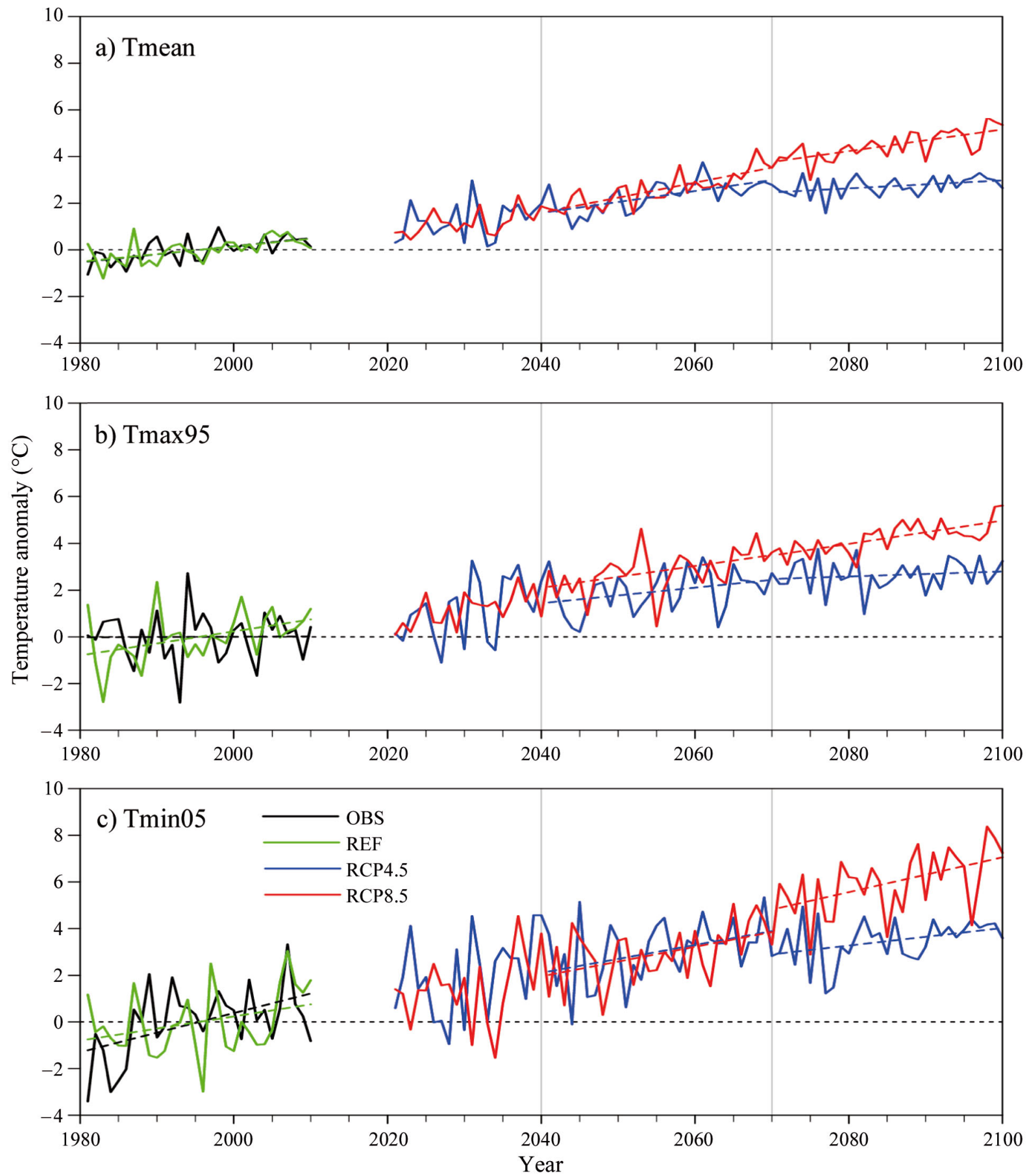

Fig. 2. Time-series of annually averaged anomalies of (a) mean temperature $\left(T_{\text {mean }}\right)$, (b) maximum temperature above $95 \%$ ( $\left.T_{\max 95}\right)$ and (c) minimum temperature below $5 \%\left(T_{\min 05}\right)$ with respect to the reference period (REF; 1981-2010). Their trends covering three 30 yr periods (1981-2010, 2041-2070 and 2071-2100) are separately indicated by dashed lines with the same color

RCP4.5 and RCP8.5 show different behavior for the two 30 yr periods (2041-2070 vs. 2071-2100) in response to the RCP4.5 and RCP8.5 scenarios, we investigate their characteristics separately for those two periods. The first period covering 2041-2070 shows a relatively smaller difference in temperature increase between RCP4.5 and RCP8.5 (hereinafter referred to as Fut1), whereas the second period covering 2071-2100 shows a quite different rate of temperature increase in line with GHG forcings used for RCP4.5 
Table 2. Temperature. Mean, coefficient of slope (trend) and its $t$-test statistics (p-value) of $T_{\text {mean }}, T_{\max 95}$ and $T_{\min 05}$ derived from observation (OBS) and reference (REF), RCP4.5 and RCP8.5 simulations during the REF (1981-2010), Fut1 (2041-2070) and Fut 2 (2071-2100) periods. * Statistical significance at the $95 \%$ confidence level

\begin{tabular}{|c|c|c|c|c|c|}
\hline & & Variable & Mean & Trend & $\mathrm{p}$ \\
\hline \multirow{3}{*}{\multicolumn{2}{|c|}{ OBS }} & $T_{\text {mean }}$ & 12.57 & 0.0348 & $0.000476^{*}$ \\
\hline & & $T_{\max 95}$ & 32.69 & 0.0013 & $0.004638^{*}$ \\
\hline & & $T_{\min 05}$ & -9.52 & 0.0839 & $0.000396^{*}$ \\
\hline \multirow{3}{*}{\multicolumn{2}{|c|}{ REF }} & $T_{\text {mean }}$ & 11.66 & 0.0329 & $0.001069^{*}$ \\
\hline & & $T_{\max 95}$ & 29.31 & 0.0515 & $0.002667^{*}$ \\
\hline & & $T_{\min 05}$ & -9.36 & 0.0519 & $0.000313^{*}$ \\
\hline \multirow[t]{6}{*}{$\mathrm{RCP} 4.5$} & Fut1 & $T_{\text {mean }}$ & 13.97 & 0.0471 & $0.000143^{*}$ \\
\hline & & $T_{\max 95}$ & 31.27 & 0.0333 & $0.000278^{*}$ \\
\hline & & $T_{\min 05}$ & -6.33 & 0.0595 & $0.00095^{*}$ \\
\hline & Fut2 & $T_{\text {mean }}$ & 14.39 & 0.0171 & $0.049097^{*}$ \\
\hline & & $T_{\max 95}$ & 31.98 & 0.0108 & 0.064665 \\
\hline & & $T_{\min 05}$ & -5.80 & 0.0394 & $0.0076825^{*}$ \\
\hline \multirow[t]{6}{*}{ RCP8.5 } & Fut1 & $T_{\text {mean }}$ & 14.25 & 0.0643 & $0.000000^{*}$ \\
\hline & & $T_{\max 95}$ & 32.14 & 0.0468 & $0.000000^{*}$ \\
\hline & & $T_{\min 05}$ & -6.43 & 0.0633 & $0.000012^{*}$ \\
\hline & Fut2 & $T_{\text {mean }}$ & 16.14 & 0.0465 & $0.000040^{*}$ \\
\hline & & $T_{\max 95}$ & 33.73 & 0.0545 & $0.000096^{*}$ \\
\hline & & $T_{\min 05}$ & -3.14 & 0.0936 & $0.000001^{*}$ \\
\hline
\end{tabular}

and RCP8.5 (hereinafter referred to as Fut2). Table 2 also includes the mean value for each selected period. In particular, comparison of the mean value between observation (OBS) and REF explicitly reveals the bias of the WRF simulation. As indicated by Ahn et al. (2013), $T_{\text {mean }}$ tends to be underestimated compared to OBS, but by $<1^{\circ} \mathrm{C} . T_{\max 95}$ and $T_{\min 05}$ derived from REF show quite different performance. $T_{\min 05}$ is mostly equal to OBS, but $T_{\max 95}$ shows a relatively large bias. Indeed, the cold bias of $T_{\text {mean }}$ is attributed to $T_{\text {max }}$ rather than to $T_{\min }$ (not shown). Changes in $T_{\max 95}$ and $T_{\min 05}$ for the future period suggest that extremes based on $T_{\min }\left(T_{\max }\right)$ will decrease (increase), in particular under RCP8.5 (see Section 3.2).

Next, trend analysis of precipitation is conducted by examining not only the mean precipitation, but also the intensity and frequency of daily precipitation (Fig. 3). A precipitation event is defined as a daily precipitation value $\geq 1.0 \mathrm{~mm}$. First, changes in mean precipitation from both observation and REF do not show any readily visible trend. The intensity and frequency of daily precipitation also show a relatively weak trend compared to the temperature changes. This is mostly due to large interannual and interdecadal variability, and this is considered typical behavior of regional-scale precipitation variability (Giorgi 2005). Since Fig. 3 displays the temporal evolution of the anomaly after subtracting the climatological mean during the reference period, the trend and variability simulated by WRF show good agreement with the observed patterns. However, comparison of mean values between OBS and REF clearly reveals the systematic biases of the model (Table 3). REF tends to produce excessive occurrence of weak precipitation (not shown), which is directly associated with the main deficiency of overestimating the frequency and underestimating the intensity of daily precipitation (Table 3). This is a commonly raised problem in precipitation performance of climate modeling (e.g. Frei et al. 2003, Kusunoki \& Mizuta 2013). However, such systematic biases in the underlying model can be partly cancelled when taking the difference between REF simulation and RCP future projection, even though such a model bias could affect the magnitude of changes in response to emission forcing (Sushama et al. 2006, Hagemann \& Jacob 2007, Im et al. 2008b). In addition, Giorgi \& Coppola (2010) demonstrate that East Asia might be a region in which the model regional bias is not a dominant factor in determining the projected regional change.

Moving to the future projection, the evolution features of precipitation are quite different from those of temperature, and contain mixed features, with both increasing and decreasing trends. Despite the initial chaotic appearance of this pattern, some welldefined or common features can be derived from this complexity. The most relevant pattern appearing in the mean, intensity and frequency is the overall greater amplitude of variability in Fut2 than in Fut1. In contrast to temperature seen in the stabilized behavior during Fut2, the enhanced variability derived from RCP4.5 is roughly equivalent to that from RCP8.5. Furthermore, precipitation likely increases more under the RCP4.5 projection than under the RCP8.5 projection during 2031-2050, which is line with the results shown by Oh et al. (2014). These behaviors clearly demonstrate the fact that precipitation changes do not respond monotonically to emission forcing. Despite the general positive anomalies of mean and intensity in Fut1 and Fut2, it is difficult to find any readily apparent long-term trends in their evolution. Since the trend depends on the selected period and its length, projections derived from a short period could produce erroneous interpretation of the results, which highlights the need for a multidecadal length of simulation. Unlike the mean and intensity of daily precipitation, the trend of frequency 

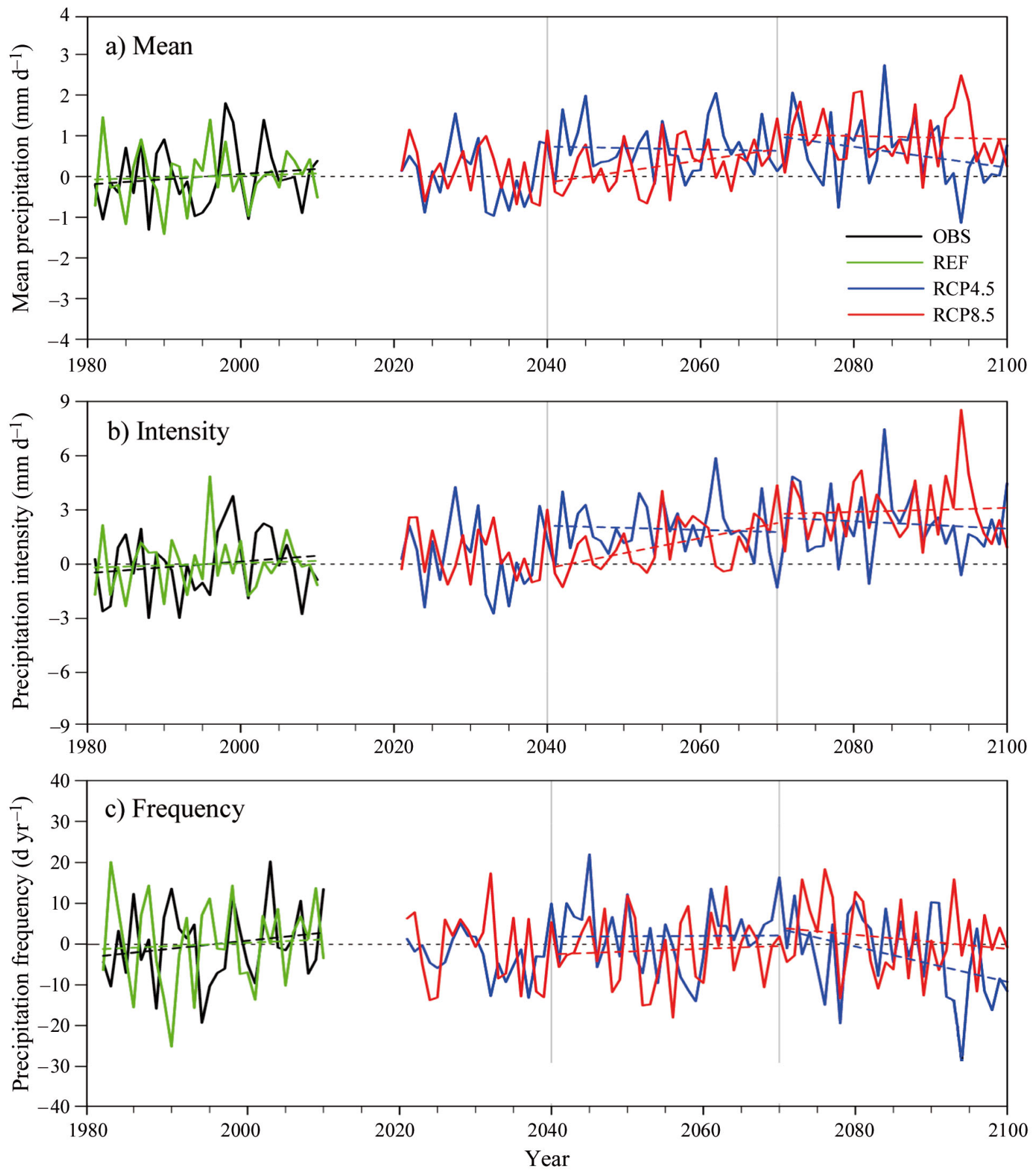

Fig. 3. Same as in Fig. 2 but for (a) mean, (b) intensity and (c) frequency of daily precipitation

declines during Fut2, in particular from RCP4.5. Such changes in the characteristics of precipitation at the end of the 21st century show agreement with previous studies, demonstrating that the mode of precipitation tends to change with less frequent but more intense events, leading to higher hydroclimatic intensity under global warming (Giorgi et al. 2011)
Based on Table 3, the statistical significance of the precipitation trend is very limited. However, the fact that no trend is statistically significant does not necessarily mean that there is no trend of environmental significance (Bae et al. 2008). For example, the enhanced intensity from RCP8.5 is seemingly visible during Fut2, but its trend is not clear and it is 
Table 3. Precipitation. Mean, coefficient of slope (trend) and its $t$-test statistics ( $\mathrm{p}$-value) of mean, intensity and frequency of daily precipitation derived from observation (OBS) and reference (REF), RCP4.5 and RCP8.5 simulations during the REF (1981-2010), Fut1 (2041-2070) and Fut2 (2071-2100) periods. ${ }^{*}$ Statistical significance at the $95 \%$ confidence level

\begin{tabular}{|c|c|c|c|c|c|}
\hline & & Variable & Mean & Trend & $\mathrm{p}$ \\
\hline \multirow{3}{*}{\multicolumn{2}{|c|}{ OBS }} & Mean & 5.70 & 0.013 & 0.441834 \\
\hline & & Intensity & 16.42 & 0.032 & 0.410739 \\
\hline & & Frequency & 81.55 & 0.196 & 0.325846 \\
\hline \multirow{3}{*}{\multicolumn{2}{|c|}{ REF }} & Mean & 4.16 & 0.005 & 0.732346 \\
\hline & & Intensity & 12.94 & 0.013 & 0.698788 \\
\hline & & Frequency & 115.10 & 0.081 & 0.726538 \\
\hline \multirow[t]{6}{*}{$\mathrm{RCP} 4.5$} & Fut1 & Mean & 4.84 & -0.026 & 0.144025 \\
\hline & & Intensity & 14.89 & -0.012 & 0.721716 \\
\hline & & Frequency & 117.11 & 0.010 & 0.955728 \\
\hline & Fut2 & Mean & 4.75 & -0.026 & 0.144025 \\
\hline & & Intensity & 15.20 & -0.021 & 0.603525 \\
\hline & & Frequency & 112.17 & -0.433 & $0.045139^{*}$ \\
\hline \multirow[t]{6}{*}{ RCP8.5 } & Fut1 & Mean & 4.44 & 0.027 & $0.027486^{*}$ \\
\hline & & Intensity & 14.00 & 0.083 & $0.003746^{*}$ \\
\hline & & Frequency & 113.69 & 0.068 & 0.710195 \\
\hline & Fut2 & Mean & 5.14 & -0.004 & 0.798016 \\
\hline & & Intensity & 15.89 & 0.011 & 0.766437 \\
\hline & & Frequency & 116.47 & -0.173 & 0.375049 \\
\hline
\end{tabular}

not significant at the $95 \%$ confidence level because the natural variability exceeds that of the linear trend.

\subsection{Characteristics of daily temperature}

Although analysis of long-term trends provides the first-order features of model behavior in response to the RCP emission scenarios, it may not be sufficiently appropriate to estimate the detailed characteristics of extremes that cause major economic damage and degrade society and ecosystems. Therefore, we attempt to examine the changes in characteristics of daily temperature and precipitation and related extremes during the 2 different future periods (e.g. Fut1 vs. Fut2).

Fig. 4 presents the annual frequency distribution of daily $T_{\text {mean }}, T_{\max }$ and $T_{\min }$ and their anomalies from 60 individual stations (not average) over South Korea (see Fig. 1b). Such a distribution is a good indicator to measure both the central tendency (e.g. mean) and dispersion (e.g. variance) of the daily values. First, the shape of the annual frequency distribution shows a bimodal structure, reflecting the contribution of different characteristics to the cold and warm seasons. $T_{\text {mean }}$ and $T_{\max }$ show similar distributions character- ized by 2 asymmetric peaks, whereas the distribution of $T_{\min }$ seems to be rather symmetric. Qualitatively, REF is capable of capturing the asymmetric bimodal structure of $T_{\text {mean }}$ and $T_{\max }$ distributions, but fails to capture the symmetric saddle-like shape seen in the observed $T_{\min }$ distribution. On the other hand, REF reproduces the lower tails of the $T_{\min }$ distribution reasonably well, but the lower tails of the $T_{\text {mean }}$ and $T_{\max }$ distributions are shifted to the left side due to the cold bias. In contrast to the $T_{\text {mean }}, T_{\max }$ and $T_{\min }$ distributions that clearly expose the model deficiency such as cold bias, their anomaly distributions subtracting mean climatology agree very closely with the observed pattern in terms of shape and variation range. This implies that systematic errors underlying mean climatology can be effectively reduced merely by using a simple statistical method. Indeed, Ahn et al. (2012) performed statistical correction based on the perturbation method using the high-resolution temperature simulated by the WRF modeling system, and thereby drastically reduced the systematic bias of raw RCM output. Future work that combines statistical correction with dynamically downscaled results will be considered for enhancing the accuracy and reliability of model simulation.

To describe the future climate statistics with respect to the reference one, we add the $T_{\text {mean, }} T_{\max }$ and $T_{\min }$ distributions derived from RCP4.5 and RCP8.5 projections during both Fut1 and Fut2 periods. Basically, the shape of the distribution does not change dramatically, but the warming from RCP4.5 and RCP8.5 mostly manifests itself as a shift of the distribution towards higher values compared to the reference climate, which is in line with those found in other future projections (e.g. Im et al. 2008a, 2011, Koo et al. 2009). In the case of RCP4.5, there are few significant differences between Fut1 and Fut2 across $T_{\text {mean }}, T_{\max }$ and $T_{\min }$, which is consistent with the temporal evolution seen in Fig. 2. However, the distribution from RCP8.5 shows a much greater shift in Fut2 than in Fut1 toward a warmer condition, as a result of the aggressive increase of GHG concentrations during Fut2. Contrasting the response behavior between RCP4.5 and RCP8.5 during Fut2 demonstrates the mitigation effect, which stresses the importance of trying to reduce GHG concentrations. Changes in anomaly distribution more clearly demonstrate the shift of the central location as well as of the tail bound in accordance with the degree of warming. During the reference period, the anomaly distribution is centered at around $0^{\circ} \mathrm{C}$, and is barely skewed by either negative or positive sides. However, for the future projection, a positive anomaly 

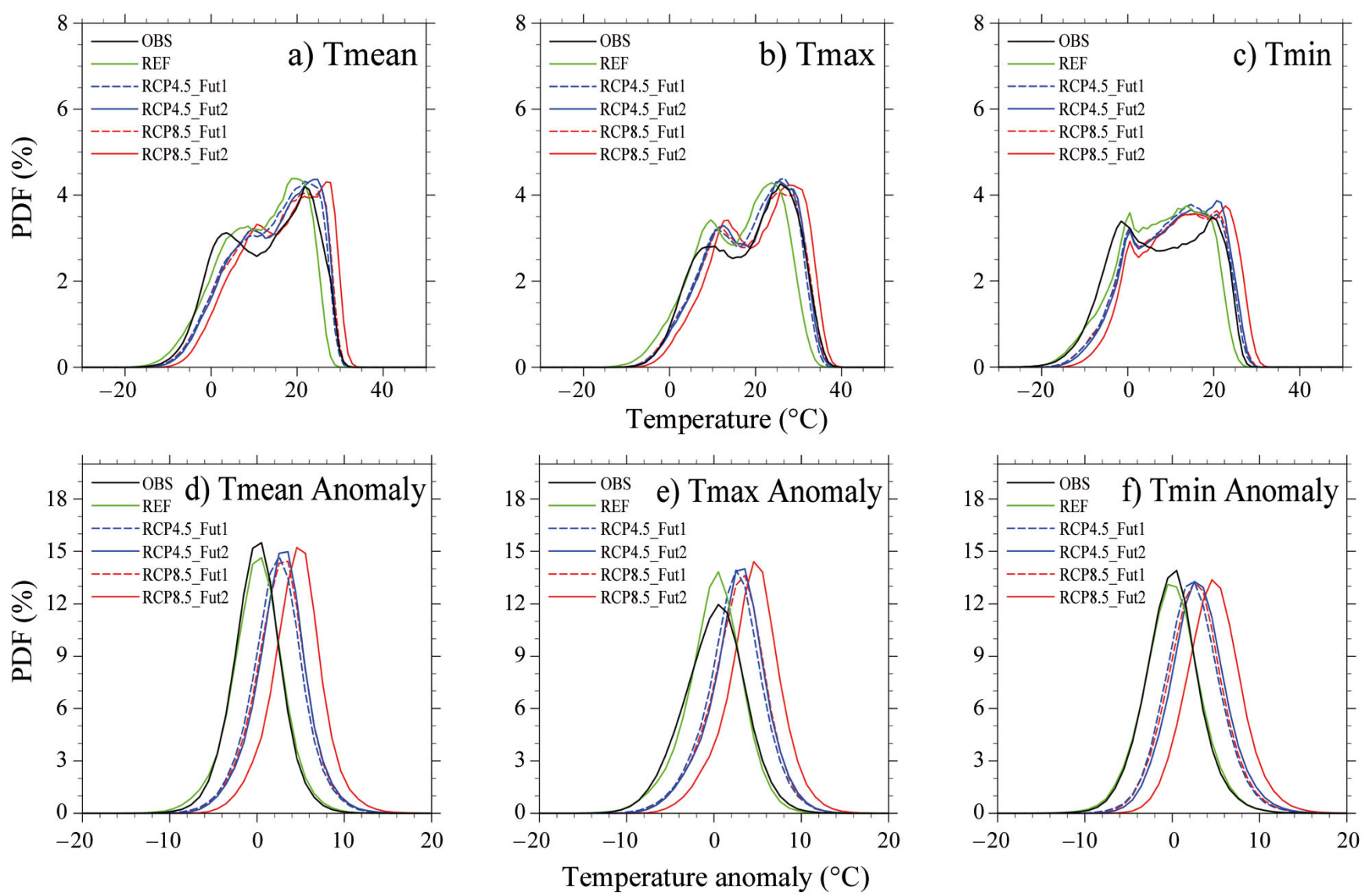

Fig. 4. Frequency distribution of daily (a) $T_{\text {mean }}$ (b) $T_{\max }$ and (c) $T_{\min }$ and (d-f) their anomalies derived from observation (OBS), reference simulation (REF), and RCP4.5 and RCP8.5 projections during Fut1 and Fut2 periods. PDF: probability density function

becomes much more likely than a negative anomaly. As expected, the difference between Fut1 and Fut2 distributions from RCP4.5 is not relevant, whereas RCP8.5 produces a notable difference between Fut1 and Fut2 distributions.

The shift of distribution has an important implication because it accompanies the changes in the extreme events due to changes in the upper and lower tail bounds. Indeed, the most severe impact of global warming will be induced by changes in the frequency and intensity of extremes events rather than by changes in the mean climate condition (e.g. Im et al. 2012, Lee et al. 2012). Figs. 5 \& 6 present the spatial distributions of changes in average temperature of extreme hot days (above the 95th percentile of the daily $T_{\max }$ ) and extreme cold days (below the 5th percentile of the daily $T_{\min }$ ), respectively, from the RCP4.5 and RCP8.5 projections. These are calculated by counting $T_{\max }$ above the 95th percentile and $T_{\min }$ below the 5th percentile in each individual year and then averaging them over the $30 \mathrm{yr}$ (e.g. REF, Fut1 and Fut2). Based on a 2-tailed $t$-test to diagnose the statistical significance of the projected changes, the changes seen in Figs. 5 \& 6 are statistically significant at the $95 \%$ confidence level over the entire region. It is evident from these figures that the average temperatures derived from both extreme hot and cold days during Fut1 and Fut2 increase consistently, but with different magnitudes across the regions and emission scenarios. Compared to the intensified extreme hot days, the reduction of extreme cold days is more pronounced, which demonstrates the asymmetric response of $T_{\max }$ and $T_{\min }$ under global warming. Regional variations show a notable difference in the spatial patterns of extreme changes in $T_{\max 95}$ and $T_{\min 05}$. A large increase appears along the south and west coastal areas in $T_{\max 95}$, whereas $T_{\min 05}$ exhibits a northwestward gradient of positive changes, and spatial details are somewhat tied to the topographical forcing with a maximum increase over the Taebaek Mountains. Such a warming amplification in the cold climate regimes (e.g. high latitude or high altitude) is 
a) RCP4.5_Fut1-REF

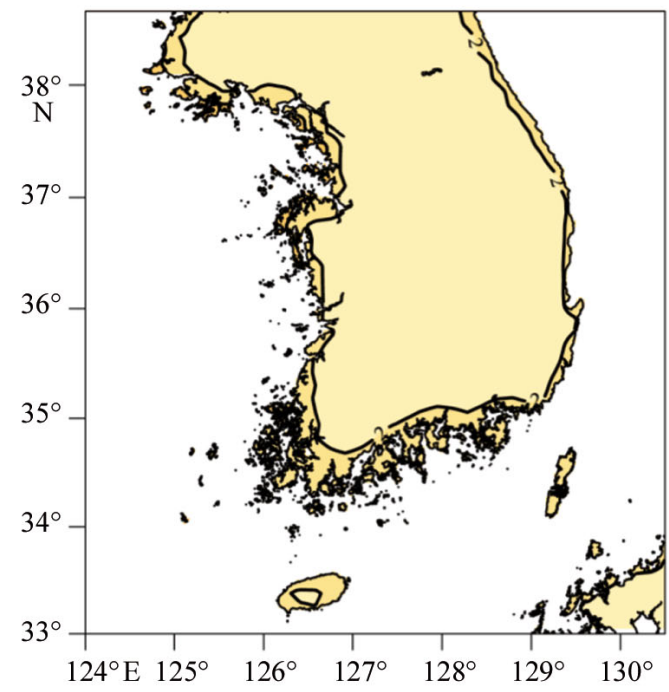

c) RCP5.5_Fut1-REF

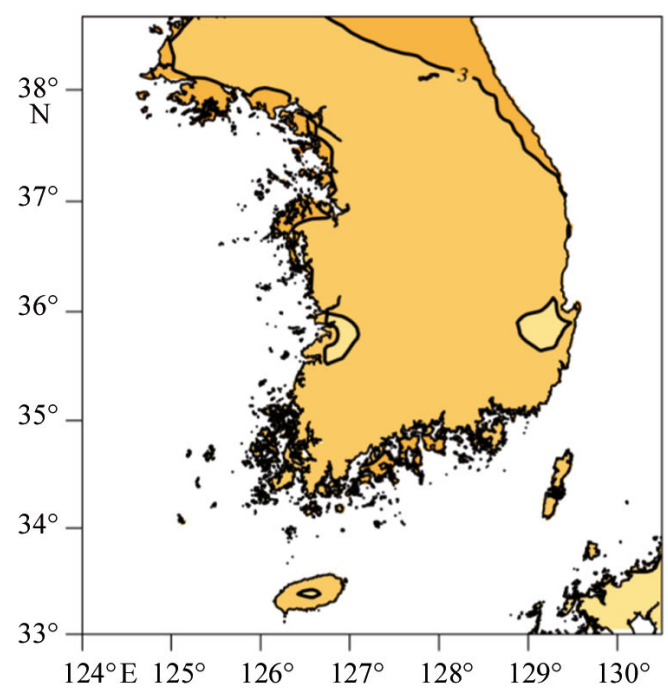

b) RCP4.5_Fut2-REF

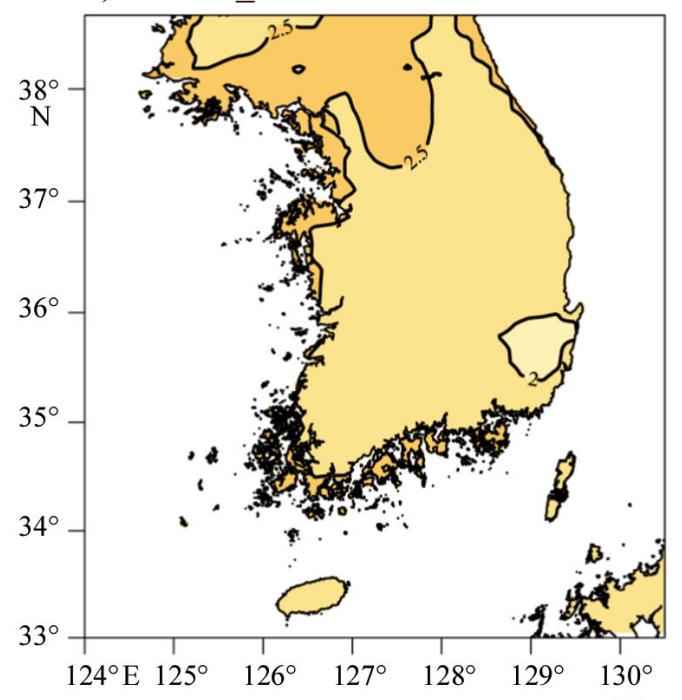

d) RCP8.5_Fut2-REF

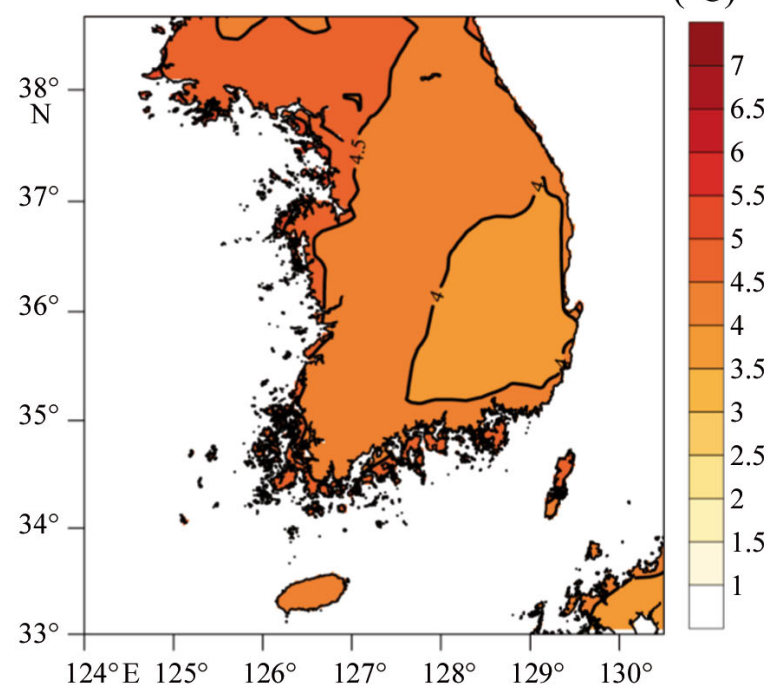

Fig. 5. Spatial distribution of changes in average temperature of extreme hot days (above 95th percentile of the daily $T_{\text {max }}$ ) from $(\mathrm{a}, \mathrm{b}) \mathrm{RCP} 4.5$ and $(\mathrm{c}, \mathrm{d}) \mathrm{RCP} 8.5$ projections during Fut1 and Fut2 periods. All changes are statistically significant at the $95 \%$ confidence level

a well-known feature that is partially associated with the snow-albedo feedback mechanism (IPCC 2007, Im et al. 2008a).

\subsection{Characteristics of daily precipitation}

Fig. 7 shows the frequency distribution of daily precipitation derived from observation, REF, and RCP4.5 and RCP8.5 projections for Fut1 and Fut2. First, REF shows good agreement with the observed distribution, except for the underestimation in the high-intensity range $>100 \mathrm{~mm} \mathrm{~d}^{-1}$. Therefore, we attribute the dry bias of the mean precipitation seen in Table 2 to the underestimation of high-intensity precipitation. Comparison of the RCP4.5 and RCP8.5 with REF reveals the enhanced probability of highintensity precipitation.

To quantitatively display the change in behavior of daily precipitation across various intensity ranges, we investigate the changes in the amount of daily precipitation as a function of intensity in order to estimate the relative contribution of changes in lowand high-intensity precipitation (Fig. 8). Initially, Fut1 and Fut2 present similar pattern of changes in daily precipitation in terms of the change sign and 
a) RCP4.5 Fut1-REF

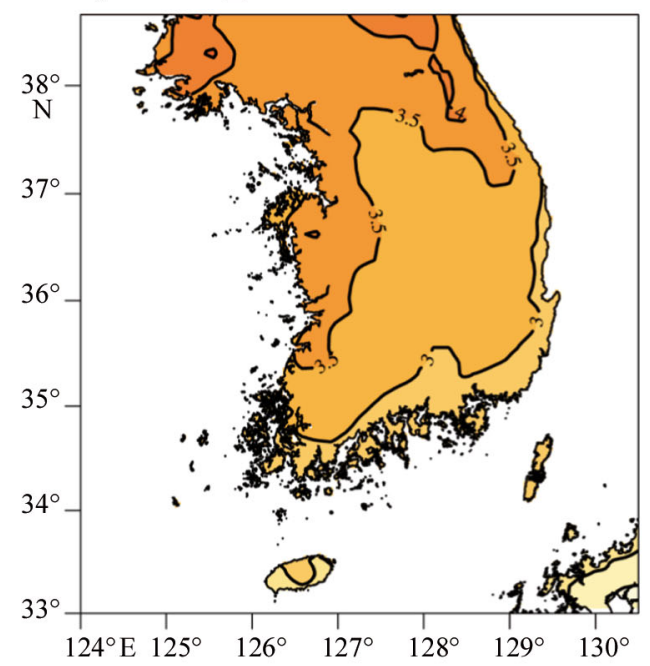

c) RCP5.5_Fut1-REF

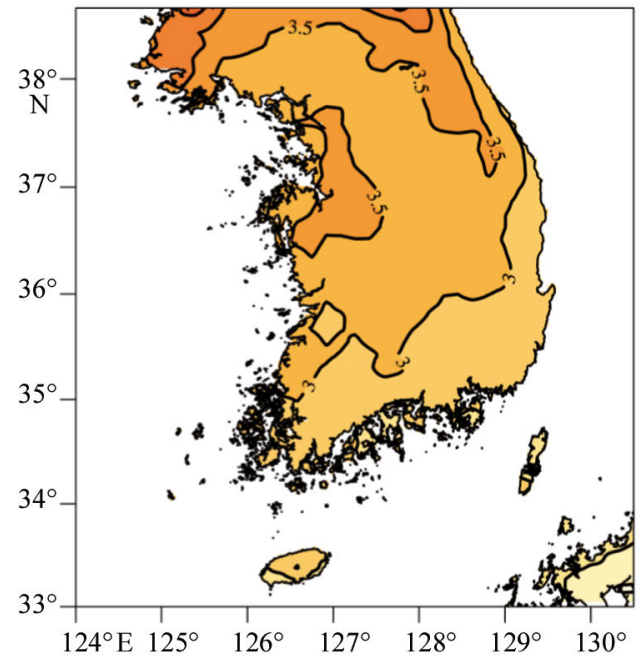

b) RCP4.5 Fut2-REF

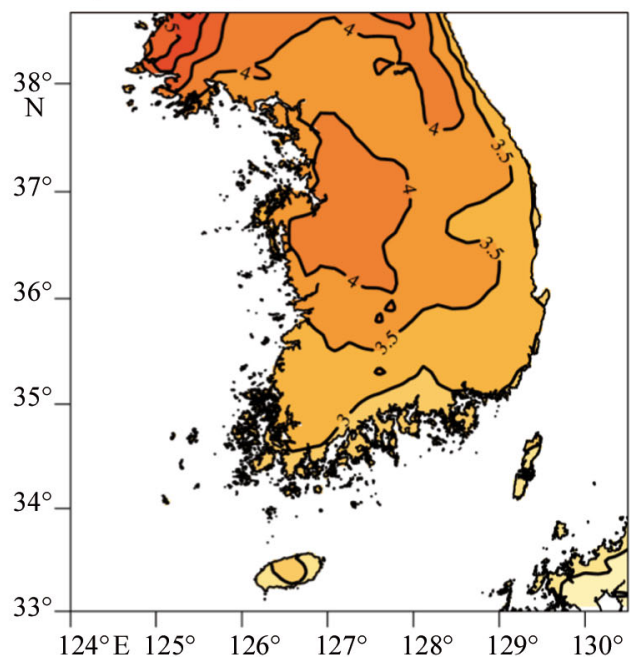

d) RCP8.5_Fut2-REF

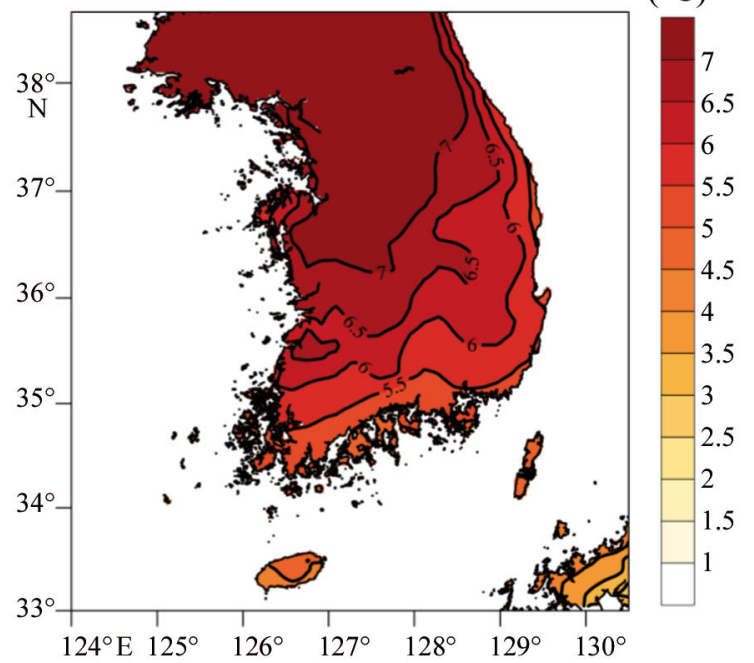

Fig. 6. Spatial distribution of changes in average temperature of extreme cold days (below 5 th percentile of the daily $T_{\text {min }}$ ) from $(\mathrm{a}, \mathrm{b}) \mathrm{RCP} 4.5$ and $(\mathrm{c}, \mathrm{d}) \mathrm{RCP} 8.5$ projections during Fut1 and Fut2 periods. All changes are statistically significant at the $95 \%$ confidence level

direction, regardless of RCP4.5 and RCP8.5. More importantly, both projections exhibit the increased contribution to total precipitation from high-intensity precipitation. An enhancement of relatively highintensity precipitation and a reduction of weakintensity precipitation are discernible, implying an intensified hydrologic cycle. This reveals the looming water management challenges in Korea under global warming (Jung et al. 2013).

This behavioral change in the precipitation characteristics is responsible for the changes in extreme precipitation. We used 2 indices to measure the frequency and intensity of heavy precipitation: the changes in the number of days in which the daily precipitation is $>100 \mathrm{~mm}$, which is the threshold level for severe weather alerts by the KMA (Fig. 9); and the intensity exceeding the 95th percentile precipitation (Fig. 10). In Figs. $9 \&$ 10, overlaid dots indicate the areas where the changes are statistically significant at the $90 \%$ confidence level. While the temperature-based extremes exhibit robust statistical significance at the $95 \%$ confidence level over the entire domain (see Figs. 5 \& 6), the statistical significance of changes in precipitation-based extremes is restricted to some parts of the simulated area. In particular, intensity changes in heavy precipitation show low statistical confidence, and thus results for this should be interpreted with caution. From a statistical point 

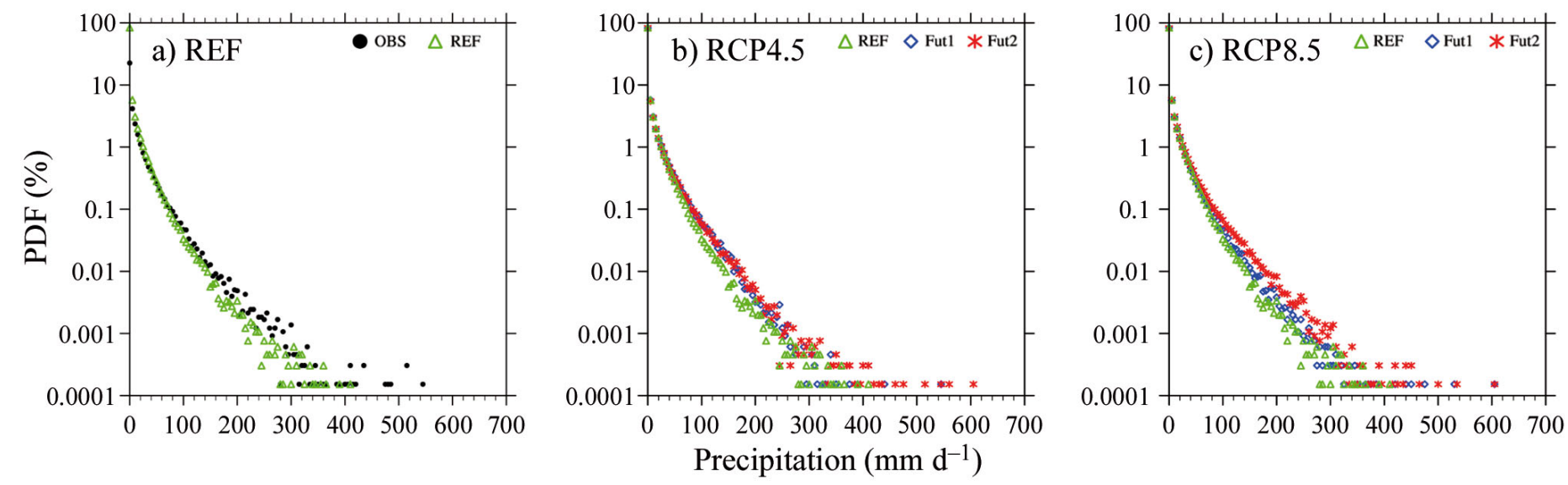

Fig. 7. Frequency distribution of daily precipitation derived from (a) observation (OBS) and reference simulation (REF), and (b) RCP4.5 and (c) RCP8.5 projections during Fut1 and Fut2 periods. The REF distribution denoted by the green triangle in (a) is the same as that in (b) and (c). PDF: probability distribution function

of view, the relatively low confidence of the projected summer precipitation is probably caused by its large natural variability (Im et al. 2008a). In spite of the complexity due to localized spatial variation, the dominant pattern is an enhancement in both frequency and intensity of heavy precipitation. In particular, the southern part of Korea is prone to extreme precipitation, which increases the vulnerability to flooding under global warming. This change might be coupled with the changes in the summer monsoon because most of the heavy precipitation events over South Korea are associated with the development of the summer monsoon (Im et al. 2008a). Consistent with our result, several studies have supported the intensification of the East Asian summer monsoon under global warming based on CMIP5 projections (e.g. Chen \& Sun 2013, Jiang \& Tian 2013, Seo et al. 2013, Lee \& Wang 2014, Qu et al. 2014, Tian et al.

a) $\mathrm{RCP} 4.5$

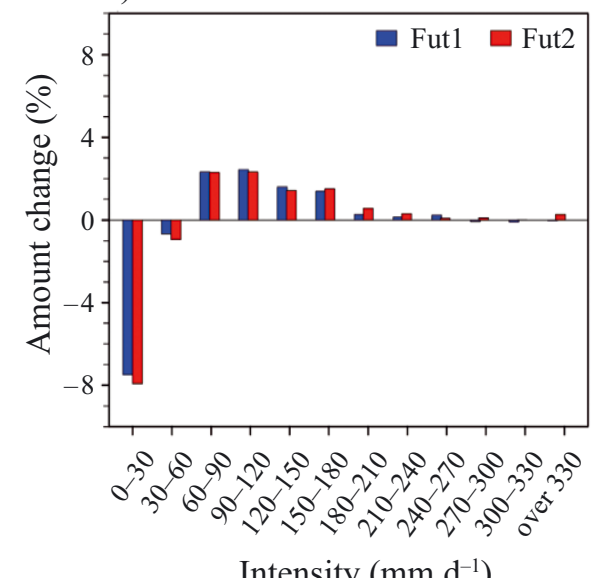

Intensity $\left(\mathrm{mm} \mathrm{d}^{-1}\right)$ b) RCP8.5

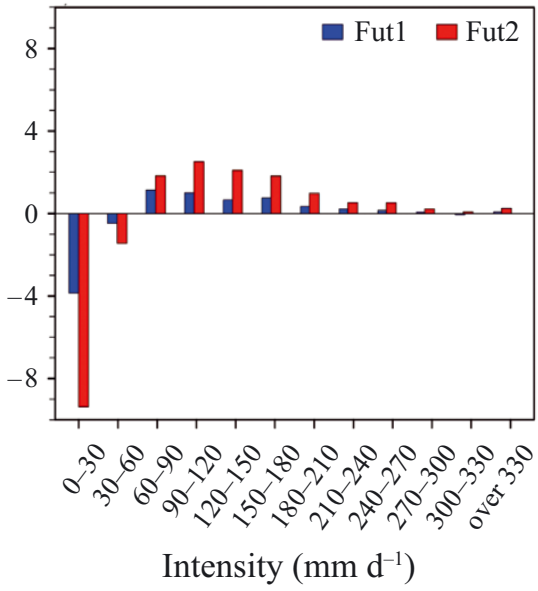

Fig. 8. Intensity dependence of changes in the amount of daily precipitation derived from (a) RCP4.5 and (b) RCP8.5 simulations
2015). As shown in Chapter 14 of the IPCC AR5 (Christensen et al. 2013), CMIP5 projections indicate a likely increase in both the circulation and rainfall of the East Asian summer monsoon through the 21st century. There is a growing consensus that atmospheric warming will increase atmospheric water holding capacity, which can lead to increase in rainfall. However, there are considerable uncertainties regarding future changes in monsoon circulation strength, and this subject, therefore, remains debatable. Indeed, Tanaka et al. (2005) and Ueda et al. (2006) contend that monsoon circulation will be weakened in spite of the increase in rainfall.

In order to describe the statistical likelihood of extreme events in daily precipitation, the return levels obtained by fitting the generalized extreme value (GEV) distribution are presented. Fig. 11 shows box plots of the return levels of annual maximum precipitation corresponding to the 20 and 50 yr return periods over 60 stations derived from REF, RCP4.5 and RCP8.5 during Fut1 and Fut2. A box plot is a convenient way of graphically depicting properties of data in terms of quartiles and extremes. In general, RCP4.5 and RCP8.5 present a similar direction of changes in return levels of annual maximum precipitation occurring at 20 and $50 \mathrm{yr}$ intervals. For both RCP4.5 and RCP8.5, the upper ends of the whiskers are significantly increased in Fut2, even without a dominant increase in median values, and this behavior is more relevant in the $50 \mathrm{yr}$ return period than in the 20 yr return 
a) RCP4.5 Fut1-REF

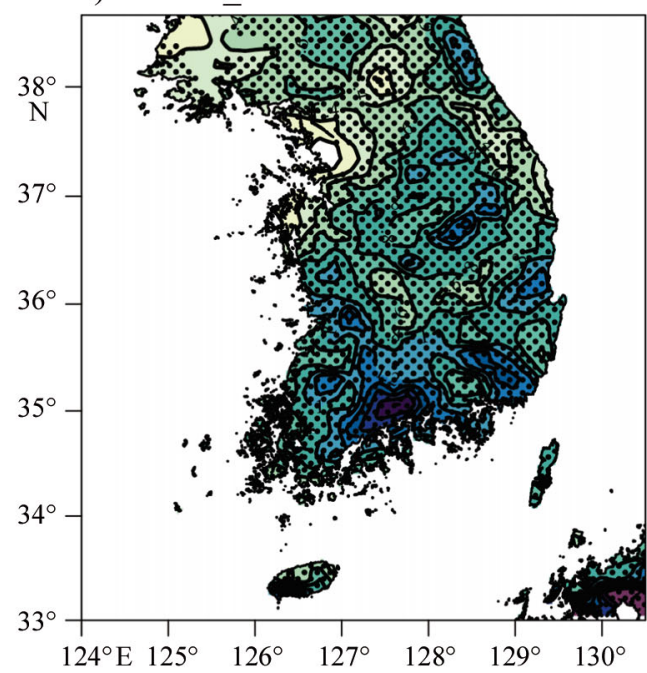

c) RCP5.5_Fut1-REF

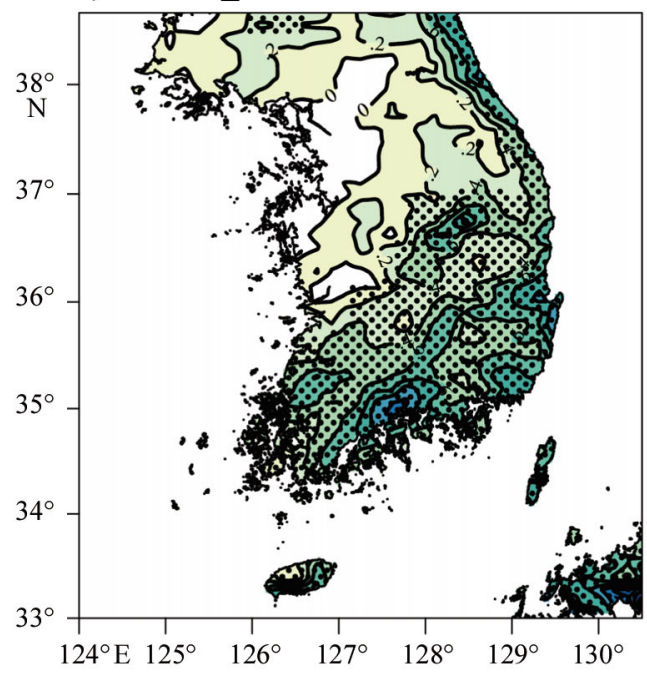

b) RCP4.5 Fut2-REF

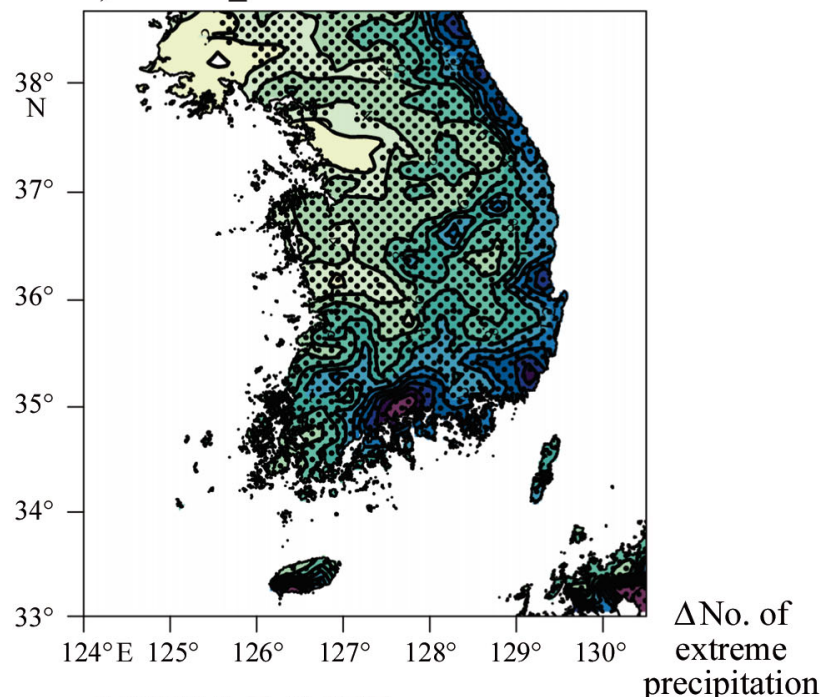

d) RCP8.5 Fut2-REF

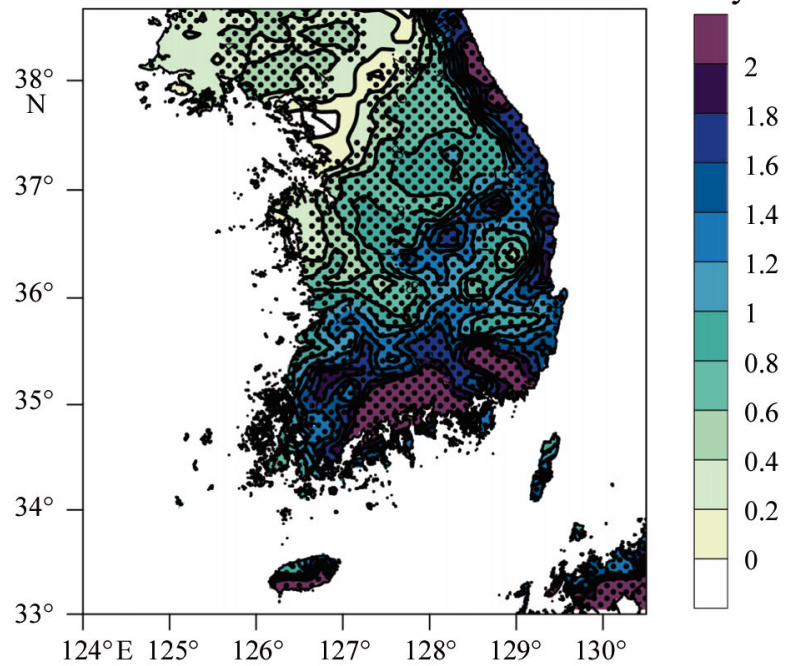

Fig. 9. Spatial distribution of changes in the number of days per year with extreme precipitation $>100\left(\mathrm{~mm} \mathrm{~d}^{-1}\right)$ from $(\mathrm{a}, \mathrm{b})$ RCP4.5 and (c,d) RCP8.5 projections during Fut1 and Fut2 periods. Superimposed black dots indicate the areas where the changes are statistically significant at the $90 \%$ confidence level

period. Much higher future values compared to their corresponding values in the reference climate indicate a more intense heavy precipitation in the future warmer climate over South Korea. For example, the intensity of extreme events occurring at a $50 \mathrm{yr}$ interval could be about $800 \mathrm{~mm} \mathrm{~d}^{-1}$ in Fut2 compared to less than $500 \mathrm{~mm} \mathrm{~d}^{-1}$ in the present climate. This implies a greater vulnerability to flood hazards due to an increased probability of more severe extreme events, which is in line with previous studies that assessed the changes in extreme precipitation due to global warming (Im et al. 2012, Sung et al. 2012, Seo et al. in press).

\section{SUMMARY AND DISCUSSION}

In this study, we have presented regional changes in 21st century temperature and precipitation over South Korea from the latest generation of highresolution downscaled projection $(12.5 \mathrm{~km})$ under the RCP4.5 and RCP8.5 scenarios adopted by IPCC AR5. This updated projection will support the further development of previous findings based on the Fourth Assessment Report (AR4) framework (e.g. global projections participating in the CMIP3 project and the Special Report on Emissions Scenarios [SRES] emission scenarios), while also improving 
a) RCP4.5 Fut1-REF

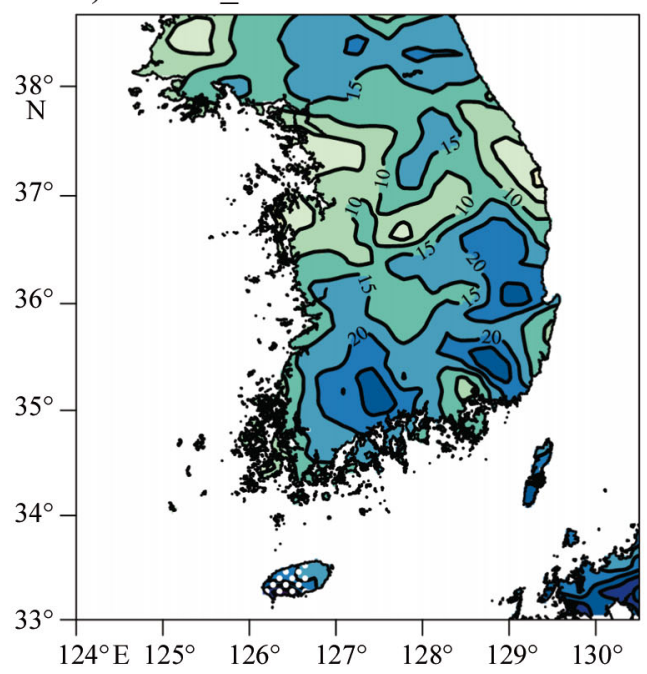

c) RCP5.5_Fut1-REF

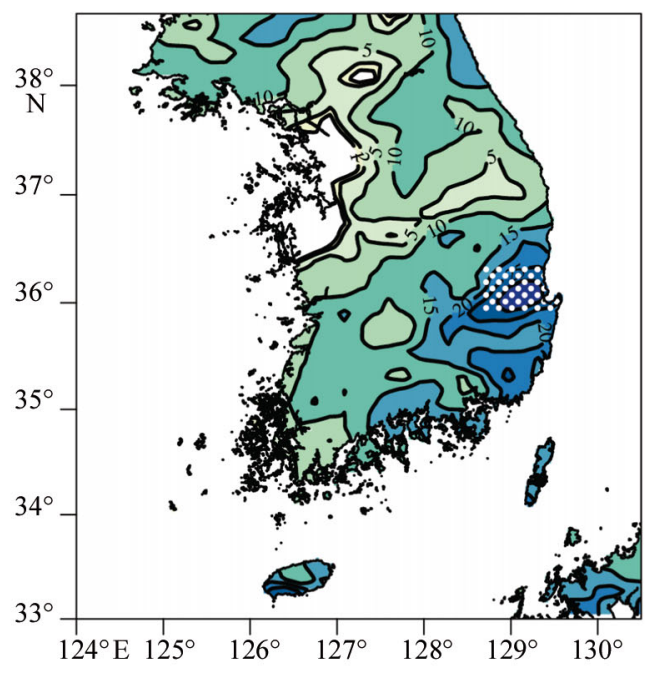

b) RCP4.5 Fut2-REF

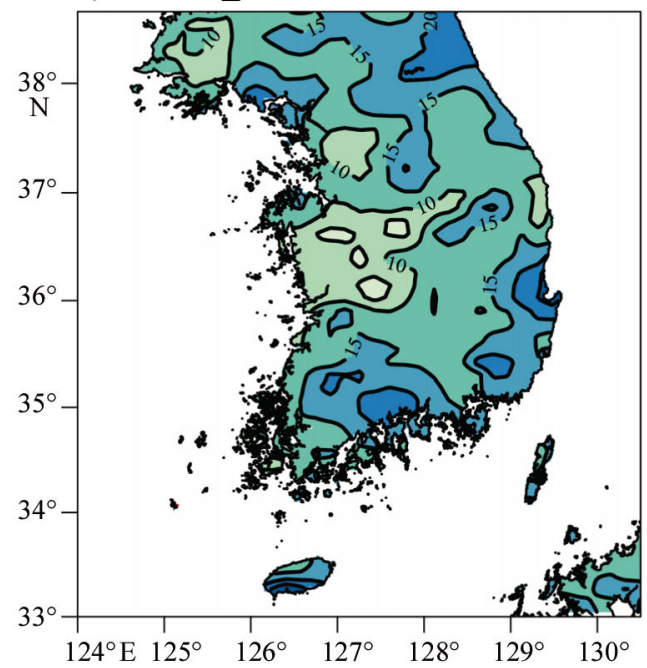

d) RCP8.5_Fut2-REF

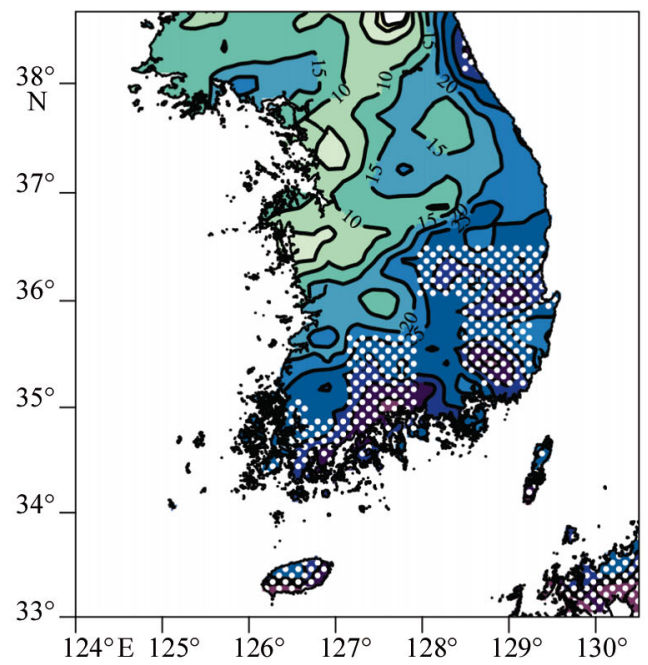

$\Delta$ Precipitation intensity $\left(\mathrm{mm} \mathrm{d}^{-1}\right)$

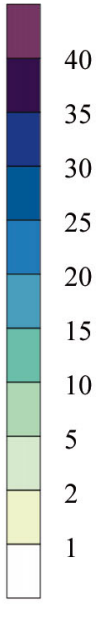

Fig. 10. Spatial distribution of changes in precipitation intensity $\left(\mathrm{mm} \mathrm{d}^{-1}\right)$ above the 95 th percentile from $(\mathrm{a}, \mathrm{b}) \mathrm{RCP} 4.5$ and $(\mathrm{c}, \mathrm{d})$ RCP8.5 projections during Fut1 and Fut2 periods. Superimposed white dots indicate the areas where the changes are statistically significant at the $90 \%$ confidence level

the model-based projections of climate changes over the region.

For the fine-scale climate information $(12.5 \mathrm{~km})$ suitable for representing the geographical complexity of the Korean peninsula, a dynamical downscaling system composed of HadGEM2-AO and the WRF model chain is applied within the framework of the national downscaling project in Korea. Regarding the validity of the reference simulation (19812010), the downscaled result performs reasonably well in capturing the trends and means of temperature and precipitation in spite of some systematic biases. For the future projection, the general characteristics of warming enhancements and precipitation changes are mostly in agreement with previous generation models (i.e. downscaling of IPCC AR4 participant models reported by Koo et al. 2009, Im et al. 2011, 2012). More specifically, we present the following main findings derived from this latest regional climate projection:

(1) The temperature response is roughly proportional to the GHG concentrations. Therefore, the difference in the temporal evolution of temperature derived from RCP4.5 and RCP8.5 is directly attributed to the difference between the RCP4.5 and RCP8.5 emission scenarios. While $T_{\text {mean }}$ from the RCP8.5 projection is sharply accelerated by more than $5^{\circ} \mathrm{C}$ by the end of the $21 \mathrm{st}$ century, $T_{\text {mean }}$ from 


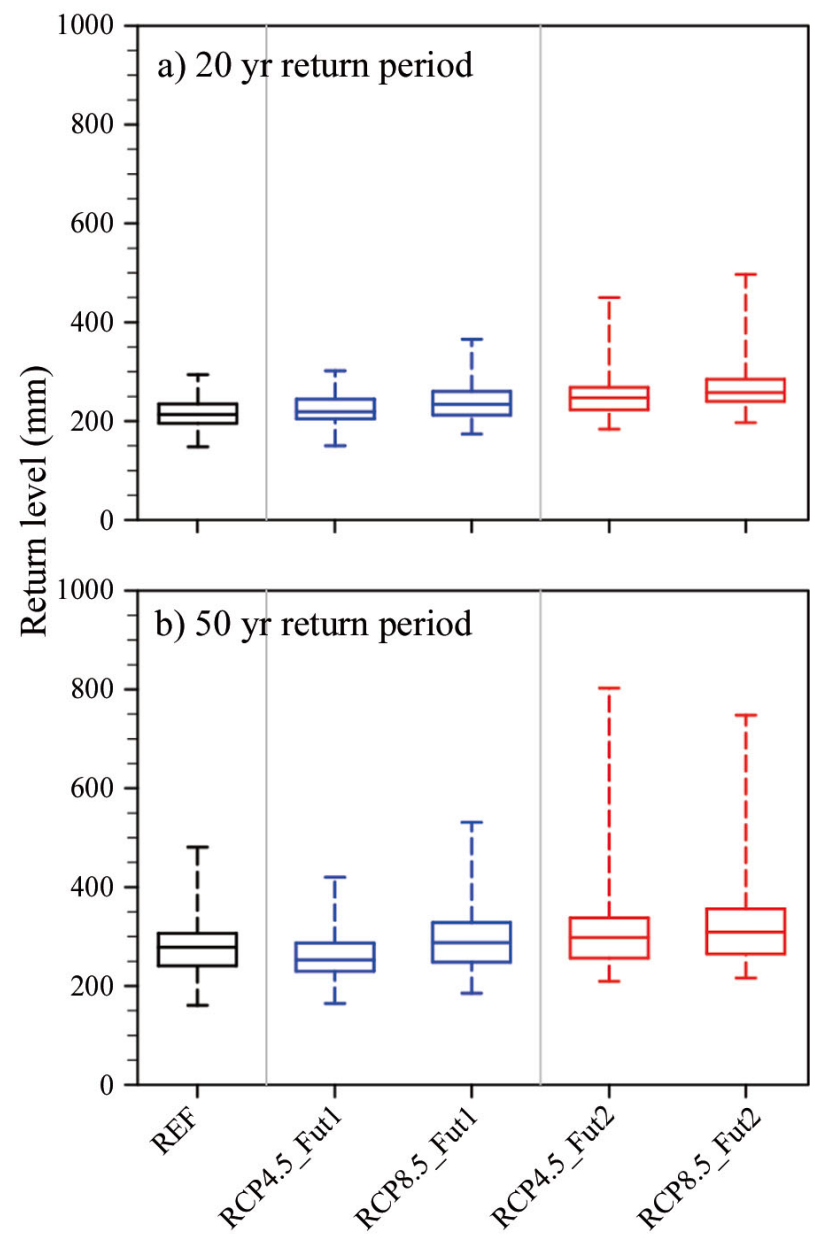

Fig. 11. Box plots of (a) 20 yr and (b) 50 yr return levels of annual maximum precipitation (daily timescale) derived from reference (REF), RCP4.5 and RCP8.5 simulations during Fut1 and Fut2 periods

the RCP4.5 projection presents a stabilization in warming after the mid to late 21 st century. In addition to $T_{\text {mean }}, T_{\max }$ and $T_{\min }$ distributions also show a differentiated response between RCP8.5 and RCP4.5 projections, which implies a large impact of mitigation. As a result of shifts in the mean value rather than the changes in kurtosis (e.g. variability) or skewness (e.g. asymmetry) of the $T_{\max }$ and $T_{\min }$ distributions, the changes in the hot and cold extremes appear to correspond to the shifts in the upper and lower tail bounds, respectively. Extreme cold days (below $5 \%$ of $T_{\min }$ ) are reduced and extreme hot days (above $95 \%$ of $T_{\max }$ ) are enhanced across the whole region of South Korea. In particular, the degree of warming is more pronounced in $T_{\min }$ from the RCP8.5 projection during Fut2.

(2) Precipitation changes do not respond monotonically to emission forcing. Although there is no rele- vant long-term trend of annual mean precipitation, RCP4.5 and RCP8.5 consistently project an enhancement of relatively high-intensity precipitation and a reduction of weak-intensity precipitation in the warmer climate. Furthermore, RCP4.5 and RCP8.5 provide a strong positive anomaly of intensity of daily precipitation and a decreasing trend of frequency of daily precipitation during Fut2 (2071-2100). These changes in the daily precipitation characteristics reflect the intensified hydrologic cycle with less frequent but more intense precipitation events, implying that water resources will face greater vulnerability as a result of global warming. The changes in the intensity and frequency of extreme precipitation are also relevant. The number of days with daily precipitation $>100 \mathrm{~mm}$ and the intensity of daily precipitation exceeding the 95th percentile are consistently increased, in particular in the southern part of South Korea. RCP4.5 and RCP8.5 also suggest an increased probability of extreme precipitation with 20 and $50 \mathrm{yr}$ return periods. Furthermore, as Korea frequently suffers localized heavy rainfall of high intensity over a short period (Im et al. 2012, 2013), we plan to intensively examine the sub-daily (i.e. $3 \mathrm{~h}$ ) precipitation in order to assess the accurate characteristics of extremely heavy precipitation and the related vulnerability of water resources.

In summary, this study suggests that climate change resulting from elevated GHG concentrations may have significant potential impacts over South Korea, not only in terms of the magnitude of change, but also in terms of shifts in the distribution of vulnerable regions, which is in line with similar previous studies. Since this study presents future projections based on only 1 global model (i.e. HadGEM-AO) and 1 regional model (i.e. WRF), considerable uncertainties remain. In this regard, we cannot make any specific conclusion based solely on the perspective examined in this study. Nevertheless, we would like to emphasize the general consistency between the behavior of future climate simulated by the HadGEM-AO and WRF and by other projections, which supports the strength of our model chain used in this study. For example, the HadGEM-AO projection over our target region is not markedly different from that of the CMIP5 multi-model ensemble mean. The increases in temperature and precipitation around the Korean peninsula projected by HadGEMAO (Baek et al. 2013) are consistent with the CMIP5 multi-model ensemble mean reported in $\mathrm{Qu}$ et al. (2014), Lee \& Wang (2014), and Seo et al. (2013). In addition, WRF-downscaled results are also in line with other projections using different RCMs driven 
by the HadGEM-AO (e.g. Lee et al. 2014, Oh et al. 2014).

The RCP4.5 and RCP8.5 projections presented in this study will serve as one of the ensemble members for the development of a national standard scenario, and may contribute to the quantification of uncertainties by comparing with other downscaling results from different regional models. In the next step of this research project, the downscaling of other global projection (i.e. MIP-ESM: Max-Planck-Institute Earth System Model) is in progress. Ensemble projections derived from downscaling of different global projections will then be examined to provide a more robust statement with high confidence.

Acknowledgements. This work was funded by the Korea Meteorological Administration Research and Development Program under grant CATER 2012-3083 and carried out with the support of the Rural Development Administration Cooperative Research Program for Agriculture Science and Technology Development under Grant Project No. PJ009953, Republic of Korea.

\section{LITERATURE CITED}

Ahn JB, Lee J, Im ES (2012) The reproducibility of surface air temperature over South Korea using dynamical downscaling and statistical correction. J Meteorol Soc Jpn 90:493-507

Ahn JB, Hong JY, Suh MS (2013) Present-day climate of the Korean Peninsula centered Northern East Asia based on CMIP5 historical scenario using fine-resolution WRF. Atmosphere 23:527-538, doi:10.14191/Atmos.2013.23.4. 527 (in Korean with English abstract)

$>$ Bae DH, Jung IW, Chang H (2008) Long-term trend of precipitation and runoff in Korean river basins. Hydrol Processes 22:2644-2656

> Baek HJ, Lee J, Lee HS, Hyun YK and others (2013) Climate change in the 21st century simulated by HadGEM2-AO under Representative Concentration Pathways. Asia-Pac J Atmos Sci 49:603-618

Chen F, Dudhia J (2001) Coupling an advanced land-surface/ hydrology model with the Penn State/ NCAR MM5 modeling system. I. Model description and implementation. Mon Weather Rev 129:569-585

$>$ Chen H, Sun J (2013) Projected change in East Asian summer monsoon precipitation under RCP scenario. Meteorol Atmos Phys 121:55-77

Cho NS, Lee TY (2006) A numerical study of multiple convection bands over the Korean peninsula. J Korean Meteorol Soc 42:87-105 (http://www.komes.or.kr/journal/ 02.html)

Christensen JH, Kumar KK, Aldrian E, An SI and others (2013) Climate phenomena and their relevance for future regional climate change. In: Stocker TF, Qin D, Plattner GK, Tignor $M$ and others (eds) Climate change 2013: the physical science basis. Contribution of Working Group I to the Fifth Assessment Report of the Intergovernmental Panel on Climate Change. Cambridge University Press, Cambridge, p 1217-1308
Collins WD, Hackney JK, Edwards DP (2002) An updated parameterization for infrared emission and absorption by water vapor in the National Center for Atmospheric Research Community Atmosphere Model. J Geophys Res Atmos 107:4664, doi:10.1029/2001JD001365

Frei C, Christensen JH, Deque M, Jacob D, Jones RG, Vidale PL (2003) Daily precipitation statistics in regional climate models: evaluation and intercomparison for the European Alps. J Geophys Res Atmos 108:4124, doi: 10.1029/2002JD002287

Gao XJ, Zhao ZC, Ding YH, Huang RH, Giorgi F (2001) Climate change due to greenhouse effects in China as simulated by a regional climate model. Adv Atmos Sci 18:1224-1230

Gao XJ, Yu Y, Zhao Z, Pal JS, Giorgi F (2006) On the role of resolution and topography in the simulation of East Asia precipitation. Theor Appl Climatol 86:173-185

> Gao XJ, Shi Y, Giorgi F (2011) A high resolution simulation of climate change over China. Sci China Earth Sci 54: 462-472

Gao XJ, Shi Y, Zhang D, Wu J, Giorgi F, Ji Z, Wang Y (2012) Uncertainties in monsoon precipitation projections over China: result from two high-resolution RCM simulations. Clim Res 52:213-226

Gao XJ, Wang ML, Giorgi F (2013) Climate change over China in the 21st century as simulated by BCC_CSM1.1RegCM4.0. Atmos Ocean Sci Lett 6:381-386

$>$ Giorgi F (2005) Interdecadal variability of regional climate change. Meteorol Atmos Phys 89:1-15

> Giorgi F, Coppola E (2010) Does the model regional bias affect the projected regional climate change? An analysis of global model projections. Clim Change 100:787-795

Giorgi F, Jones C, Asrar GR (2009) Addressing climate information needs at the regional level: the CORDEX framework. WMO Bull 58:175-183

- Giorgi F, Im ES, Coppola E, Diffenbaugh NS, Gao XJ, Mariotti L, Shi Y (2011) Higher hydroclimatic intensity with global warming. J Clim 24:5309-5324

Hagemann S, Jacob D (2007) Gradient in the climate change signal of European discharge predicted by a multi-model ensemble. Clim Change 81:309-327

> Hong JY, Ahn JB (in press) Changes of early summer precipitation in the Korean Peninsula and nearby regions based on RCP simulations. J Clim,

> Hong SY, Lee JW (2009) Assessment of the WRF model in reproducing a flash-flood heavy rainfall event over Korea. Atmos Res 93:818-831

> Hong SY, Dudhia J, Chen SH (2004) A revised approach to ice microphysical processes for the bulk parameterization of clouds and precipitation. Mon Weather Rev 132:103-120

$>$ Hong SY, Noh Y, Dudhia J (2006) A new vertical diffusion package with an explicit treatment of entrainment processes. Mon Weather Rev 134:2318-2341

Hong SY, Oh SG, Suh MS, Lee DK, Ahn JB, Kang HS (2013) Future climate changes over North-East Asian region simulated by RegCM4 based on the RCP scenarios. J Clim Res 8:27-44 (http://jcr.re.kr/)

Im ES, Park EH, Kwon WT, Giorgi F (2006) Present climate simulation over Korea with a regional climate model using a one-way nested system. Theor Appl Climatol 86: 187-200

Im ES, Kwon WT, Ahn JB, Giorgi F (2007) Multi-decadal scenario simulation over Korea using a one-way doublenested regional climate model system. I. Recent climate simulation (1971-2000). Clim Dyn 28:759-780 
Im ES, Ahn JB, Kwon WT, Giorgi F (2008a) Multi-decadal scenario simulation over Korea using a one-way doublenested regional climate model system. II. Future climate projection (2021-2050). Clim Dyn 30:239-254

Im ES, Gutowski WJ, Giorgi F (2008b) Consistent changes in twenty-first century daily precipitation from regional climate simulations for Korea using two convection parameterizations. Geophys Res Lett 35:L14706, doi:10.1029/ 2008GL034126

> Im ES, Jung IW, Bae DH (2011) The temporal and spatial structure of recent and future trends in extreme indices over Korea from a regional climate projection. Int J Climatol 31:72-86

Im ES, Lee BJ, Kwon JH, In SR, Han HO (2012) Potential increase of flood hazards in Korea due to global warming from a high-resolution regional climate simulation. AsiaPac J Atmos Sci 48:107-113

> Im ES, In SR, Han SO (2013) Numerical simulation of the heavy rainfall caused by a convection band over Korea: a case study on the comparison of WRF and CReSS. Nat Hazards 69:1681-1695

IPCC (2007) Climate change 2007: the scientific basis. Contribution of Working Group I to the Fourth Assessment Report of the Intergovernmental Panel on Climate Change. Cambridge University Press, Cambridge

IPCC (2013) Stocker TF, Qin D, Plattner GK, Tignor M and others (eds) Climate change 2013: the physical science basis. Contribution of Working Group I to the Fifth Assessment Report of the Intergovernmental Panel on Climate Change. Cambridge University Press, Cambridge

> Jiang D, Tian Z (2013) East Asian monsoon change for the 21st century: results of CMIP3 and CMIP5 models. Chin Sci Bull 58:1427-1435

Jiménez PA, Dudhia J, González-Rouco JF, Navarro J, Montávez JP, García-Bustamante E (2012) A revised scheme for the WRF surface layer formulation. Mon Weather Rev 140:898-918

Jung IW, Bae DH, Lee BJ (2013) Possible change in Korean streamflow seasonality based on multi-model climate projections. Hydrol Processes 27:1033-1045

Kain JS, Fritsch JM (1993) Convective parameterization for mesoscale models: the Kain-Fritsch scheme. The representation of cumulus convection in numerical models. Meteorol Monogr Am Meteorol Soc 24:165-170

Koo GS, Boo KO, Kwon WT (2009) Projection of temperature over Korea using an MM5 regional climate simulation. Clim Res 40:241-248

> Kusunoki S, Mizuta R (2013) Changes in precipitation intensity over East Asia during the 20th and 21st centuries simulated by a global atmospheric model with a $60 \mathrm{~km}$ grid size. J Geophys Res Atmos 118:11007-11016

Lee JW, Hong SY (2014) Potential for added value to downscaled climate extremes over Korea by increased resolution of a regional climate model. Theor Appl Climatol 117:667-677

> Lee JY, Wang B (2014) Future change of global monsoon in the CMIP5. Clim Dyn 42:101-119

> Lee MH, Ho CH, Kim J, Song CK (2012) Assessment of the changes in extreme vulnerability over East Asia due to global warming. Clim Change 113:301-321

> Lee JW, Hong SY, Chang EC, Suh MS, Kang HS (2014) Assessment of future climate change over East Asia due

Editorial responsibility: Filippo Giorgi,

Trieste, Italy to the RCP scenarios downscaled by GRIMs-RMP. Clim Dyn 42:733-747

Lim KSS, Hong SY (2010) Development of an effective double-moment cloud microphysics scheme with prognostic cloud condensation nuclei $(\mathrm{CCN})$ for weather and climate models. Mon Weather Rev 138:1587-1612

Mitchell TD, Carter TR, Jones PD, Hulme M, New M (2004) A comprehensive set of high-resolution grids of monthly climate for Europe and the globe: the observed record (1901-2000) and 16 Scenarios (2001-2100). Work Pap 55. Tyndall Centre for Climate Change Research, Norwich

> Moss RH, Edmonds JA, Hibbard KA, Manning MR and others (2010) The next generation of scenarios for climate change research and assessment. Nature 463:747-756

> Oh SK, Park JH, Lee SH, Suh MS (2014) Assessment of the RegCM4 over East Asia and future precipitation change adapted to the RCP scenarios. J Geophys Res Atmos 119: 2913-2927

Qu X, Huang G, Zhou W (2014) Consistent responses of East Asian summer mean rainfall to global warming in CMIP5 simulations. Theor Appl Climatol 117:123-131

Seo KH, Ok J, Son JH, Cha DH (2013) Assessing future changes in the East Asian Summer Monsoon using CMIP5 coupled models. J Clim 26:7662-7675

Seo YA, Lee Y, Park JS, Kim MK, Cho C, Baek HJ (in press) Assessing changes in observed and future projected precipitation extremes in South Korea. Int J Climatol, doi: 10.1002/joc.4039

Skamarock WC, Klemp JB, Dudhia J, Gill DO and others (2008) A description of the Advanced Research WRF version 3. NCAR Tech Note NCAR/TN-475+STR. National Center for Atmospheric Research, Boulder, CO

Sung JH, Kang HS, Park S, Cho C, Bae DH, Kim YO (2012) Projection of extreme precipitation at the end of 21st century over South Korea based on Representative Concentration Pathways (RCP). Atmosphere 22:221-231, doi: 10.14191/Atmos.2012.22.2.221

Sushama L, Laprise R, Caya D, Frigon A, Slivitzky M (2006) Canadian RCM projected climate change signal and its sensitivity to model errors. Int J Climatol 26:2141-2159

Tanaka HL, Ishizaki N, Nohara D (2005) Intercomparison of the intensities and trends of Hadley, Walker and monsoon circulations in the global warming projections. SOLA 1:77-80

Taylor KE, Stouffer RJ, Meehl GA (2012) An overview of CMIP5 and the experiment design. Bull Am Meteorol Soc 93:485-498

> Tian D, Guo Y, Dong W (2015) Future change and uncertainties in temperature and precipitation over China based on CMIP5 models. Adv Atmos Sci 32:487-496

Ueda H, Iwai A, Kuwako K, Hori ME (2006) Impact of anthropogenic forcing on the Asian summer monsoon as simulated by eight GCMs. Geophys Res Lett 33:L06073, doi:10.1029/2005GL025336

Yu ET, Wang HJ, Sun JQ (2010) A quick report on a dynamical downscaling simulation over China using the nested model. Atmos Ocean Sci Lett 3:325-329

Zou L, Zhou T (2013) Near future (2016-40) summer precipitation changes over China as projected by a regional climate model (RCM) under the RCP8.5 emissions scenario: comparison between RCM downscaling and the driving GCM. Adv Atmos Sci 30:806-818

Submitted: October 27, 2014; Accepted: February 11, 2015 Proofs received from author(s): May 6, 2015 